IZA DP No. 10254

What is the Added Value of Preschool? Long-Term Impacts and Interactions with a Health Intervention

Maya Rossin-Slater

Miriam Wüst

October 2016 


\title{
What is the Added Value of Preschool? Long-Term Impacts and Interactions with a Health Intervention
}

\author{
Maya Rossin-Slater \\ University of California at Santa Barbara, \\ NBER and IZA \\ Miriam Wüst \\ Danish National Centre for Social Research (SFI)
}

Discussion Paper No. 10254

October 2016

\author{
IZA \\ P.O. Box 7240 \\ 53072 Bonn \\ Germany \\ Phone: +49-228-3894-0 \\ Fax: +49-228-3894-180 \\ E-mail: iza@iza.org
}

Any opinions expressed here are those of the author(s) and not those of IZA. Research published in this series may include views on policy, but the institute itself takes no institutional policy positions. The IZA research network is committed to the IZA Guiding Principles of Research Integrity.

The Institute for the Study of Labor (IZA) in Bonn is a local and virtual international research center and a place of communication between science, politics and business. IZA is an independent nonprofit organization supported by Deutsche Post Foundation. The center is associated with the University of Bonn and offers a stimulating research environment through its international network, workshops and conferences, data service, project support, research visits and doctoral program. IZA engages in (i) original and internationally competitive research in all fields of labor economics, (ii) development of policy concepts, and (iii) dissemination of research results and concepts to the interested public.

IZA Discussion Papers often represent preliminary work and are circulated to encourage discussion. Citation of such a paper should account for its provisional character. A revised version may be available directly from the author. 


\section{ABSTRACT \\ What is the Added Value of Preschool? Long-Term Impacts and Interactions with a Health Intervention*}

We study the impact of targeted high quality preschool over the life cycle and across generations, and examine its interaction with a health intervention during infancy. Using administrative data from Denmark together with variation in the timing of program implementation between 1933 and 1960, we find lasting benefits of access to preschool at age 3 on outcomes through age 65 - educational attainment increases, income rises (for men), and the probability of survival increases (for women). Further, the benefits persist to the next generation, who experience higher educational attainment by age 25 . However, exposure to a nurse home visiting program in infancy reduces the added value of preschool. The positive effect of preschool is lowered by 85 percent for years of schooling (of the first generation) and by 86 percent for adult income among men.

JEL Classification: $\quad 138,114, \mathrm{~J} 13$

Keywords: preschool, intergenerational, interactions

Corresponding author:

Maya Rossin-Slater

Department of Economics

University of California

2127 North Hall

Santa Barbara, CA 93106-9210

USA

E-mail: maya.rossin-slater@ucsb.edu

\footnotetext{
* This paper was previously circulated under the title "Are Different Early Investments Complements or Substitutes? Long-Run and Intergenerational Evidence from Denmark". We thank Hoyt Bleakley, Gabriella Conti, Rasmus Landersø, Shelly Lundberg, Michael Mueller-Smith, Diane Schanzenbach, Jeffrey Smith, and seminar participants at UC Santa Barbara, the University of lowa, the University of Michigan, the University of Copenhagen, Lund University, Santa Clara University, the "Early Childhood Inequality Workshop" (Nuremberg), the NBER Summer Institute, and the All-California Labor Economics Conference for helpful comments. We are grateful to Peder Dam and the "DigDag" project for invaluable help with the data on Denmark's historical administrative structure. Ida Lykke Kristiansen provided excellent research assistance. The Danish Data Archive provided the data from the "Statistical Commune Data Archive." We gratefully acknowledge financial support from the Danish Council for Independent Research (grant \# 4003-00007).
} 


\section{Introduction}

A growing body of evidence traces the origins of adult well-being to individuals' early-life circumstances (Almond and Currie, 2011; Barker, 1990). This evidence, combined with the fact that the majority of parents in developed countries participate in the labor force when their children are young, has prompted fervent discussions among both researchers and policymakers on the importance of high quality preschools, especially for low-income children. For instance, President Obama's "Plan for Early Education" extends federal funds to provide all four-year-olds from U.S. families with incomes at or below 200 percent of the poverty line with a high quality public preschool. ${ }^{1}$ In Europe, the European Commission has a target that at least 95 percent of 4-year-old children are enrolled in preschool education by $2020 .^{2}$

This paper contributes to the evidence on preschools by delivering estimates of the longterm and intergenerational effects of a large targeted program in early 20th century Denmark. In the U.S., prior studies of targeted programs - including Head Start, the Perry Preschool program, and the Abecedarian Project-have thus far documented benefits for individuals into their 30s using data sets with relatively small sample sizes (Garces et al., 2002; Ludwig and Miller, 2007; Deming, 2009; Carneiro and Ginja, 2012; Campbell et al., 2014; Schweinhart et al., 2005; Heckman et al., 2010). In Scandinavia, the existing evidence on preschools comes from recent universal programs attended by children from all socio-economic backgrounds (Havnes and Mogstad, 2011, 2015; Bingley et al., 2015). We shed light on the consequences of an earlier Danish program that explicitly targeted disadvantaged children, who may have had the most to gain from regulated center-based care and education. Using population-level administrative data, we analyze the outcomes of individuals in their 50s and 60 s and the outcomes of their children through age 25 .

Additionally, we provide novel evidence on the added value of preschool for a population that received an earlier health intervention in infancy. This analysis is especially relevant for the current policy landscape in the developed world, where there is a multitude of early

\footnotetext{
${ }^{1}$ See: https://www.whitehouse.gov/the-press-office/2013/02/13/fact-sheet-president-obama-s-plan-earlyeducation-all-americans.

${ }^{2}$ See: http://ec.europa.eu/education/policy/school/early-childhood_en.
} 
childhood programs with similar eligibility criteria. ${ }^{3}$ As such, many children are likely to be exposed to more than one intervention in the early life period. Knowledge about the signs and magnitudes of the potential interaction effects between programs is imperative for efficient policy design as well as for understanding the determinants of human capital production in a framework with different stages of early childhood (Cunha and Heckman, 2007).

Yet, as noted by Almond and Mazumder (2013), the analysis of interactions between multiple interventions in an observational setting requires "lightning to strike twice"; one needs two independent, quasi-exogenous interventions affecting the same children at adjacent developmental stages. We argue that early 20th century Denmark provides such an exceptional setting - preschool access was gradually expanded around the same time as a universal nurse home visiting (NHV) program for new mothers and infants was introduced. NHV aimed at improving the health of infants through teaching mothers about the benefits of breastfeeding and a safe home environment. Importantly, some municipalities implemented the NHV program before the preschool program, while others implemented the preschool program before the NHV program, and the timing of each program's rollout was independent of the other.

We merge unique historical program data to individual-level administrative data on the population of Danish individuals born in 1930-1957. We exploit policy variation in the timing of preschool openings across 140 Danish municipalities that established a governmentapproved and regulated formal preschool by $1960 .{ }^{4}$ These preschools offered a high quality early learning environment and nutritious meals to disadvantaged children aged 3 to 7 . We find that, relative to cohorts without access to preschool in early life, cohorts born in municipalities with a preschool by age 3 have 1.6 percent more years of schooling and are 9.7 percent less likely to have only nine years of basic compulsory education. We also find that access to preschool leads to a 2 percent increase in total income measured around age 50 for males. For females, we find a 0.8 percent increase in the likelihood of surviving beyond age 65 , possibly driven by a decrease in heart disease diagnoses.

\footnotetext{
${ }^{3}$ For an overview of current early childhood programs in the U.S., see Currie and Rossin-Slater, 2015.

${ }^{4}$ To receive government approval, a preschool must follow strict quality regulations mandated by the government. See Section 2 for more details. Individuals born in the 140 ever-implementing municipalities account for approximately 53 percent of the Danish population born during this time period.
} 
Next, we provide some of the first evidence on the intergenerational impacts of preschools. While there is a vast literature documenting intergenerational correlations in measures of socio-economic status such as income, education, and IQ in both the U.S. and Europe (e.g.: Solon, 1992; Bauer and Riphahn, 2004; Lee and Solon, 2009; Black et al., 2009; Chetty et al., 2014), less is known about the impacts of an intervention that causally increases educational attainment in one generation on the education of the next generation. ${ }^{5}$ We find that children of women who had access to preschool by age 3 have 0.4 percent more years of schooling and are 6 percent less likely to only have a compulsory education by age 25 , relative to the children of women without preschool exposure.

Finally, we study whether the added value of preschool varies with earlier exposure to NHV. ${ }^{6}$ We find statistically significant negative interaction effects between exposure to NHV and preschool, suggesting that the marginal benefit of preschool is lower for children who had already been exposed to NHV as infants. Having access to NHV reduces the positive impact of preschool by 85 percent for years of schooling (of the first generation) and 86 percent for income among men. We present suggestive evidence that the impacts on women's survival beyond age 65 and the education of the second generation are reduced as well.

Our results on the interaction between preschool and NHV exposure may be considered in the context of economic models of human capital formation, which posit that there are dynamic complementarities between multiple investments at different stages of childhood and across different parameters of the child production function (Cunha and Heckman, 2007). In our setting, these models would suggest that children who are exposed to the positive health effects of NHV in infancy may benefit more from access to a stimulating environment in preschool than those without prior NHV exposure. Since we cannot identify important parameters of the human capital production function (e.g., parental investments and initial

\footnotetext{
${ }^{5}$ We are aware of only one study that has examined the intergenerational impacts of early-life conditions on the cognitive outcomes of the next generation: Black et al. (2013) show that children of individuals who were exposed to radiation in utero have lower IQ scores.

${ }^{6}$ As prior work has comprehensively analyzed the long-run effects of the NHV program, we do not focus on them here. Hjort et al. (2014) show that NHV decreased mortality at ages 45-57 and the probability of being diagnosed with cardiovascular disease during the same age range. We have also estimated the main effects of NHV using the sample and measures from the current paper. Our estimates are in line with the results presented in Hjort et al. (2014) and suggest strong long-term health effects of NHV. These results are available upon request.
} 
conditions), we do not view our results as arguing against these models. Instead, our evidence is consistent with a compensatory model of early education, in which the impacts of preschool are largest for the least advantaged children (Bitler et al., 2014; Havnes and Mogstad, 2011, 2015). However, unlike prior studies, we are able to identify heterogeneous returns to preschool across individuals who differ in their early-life environments due to a quasi-exogenous, program-driven source of variation. ${ }^{7}$ Interestingly, the large negative interaction effects between NHV and preschool exposure are consistent with two other concurrent papers studying interactions across different types of early-life investments in Bangladesh (Gunnsteinsson et al., 2014) and Mexico (Adhvaryu et al., 2015). ${ }^{8}$

The rest of the paper proceeds as follows. Section 2 provides relevant background and reviews the existing literature. Section 3 describes our data sources and sample, while Section 4 discusses our empirical methods. Section 5 presents our main results and robustness tests, and provides a discussion of the magnitudes and the possible mechanisms underlying the effects we find, while Section 6 concludes.

\section{Background and Related Literature}

\subsection{The Danish Preschool Expansion}

The Danish preschool system goes back to 1828, when the first preschool was founded. Preschools in the 19th and early 20th centuries were run by philanthropic organizations to serve children from poor families, whose mothers had to work (Pedersen et al., 2011). ${ }^{9}$ However, until 1919, these preschools were not regulated and exhibited substantial variation in quality. Preschool quality improved and became more uniform as a result of a series of laws passed between 1919 and 1951, which regulated government approval and financial support of all existing and new preschools (see Skjernbæk, various years).

\footnotetext{
${ }^{7}$ Related, a recent randomized trial of an early health intervention in Britain suggests that it provides minimal added value when implemented on top of existing health and social care programs (Robling et al., 2016; Olds, 2016).

${ }^{8}$ Specifically, Gunnsteinsson et al. (2014) study an interaction between a tornado and a randomized vitamin supplementation program in Bangladesh, while Adhvaryu et al. (2015) analyze an interaction between rainfall shocks and conditional cash transfers in Mexico. Section 2 discusses these papers in more detail.

${ }^{9}$ During the early 20th century, the Danish female labor force participation rate was between 30 and 40 percent (Olivetti, 2013).
} 
From 1919 onwards, the government offered subsidies to preschools that could be used to cover daily expenses (e.g., staff wages or rent) or to establish, improve, or expand existing centers. ${ }^{10}$ In order to apply for a subsidy, a preschool first needed to obtain government approval. Approval was granted to preschools that provided adequate facilities, had a board and a qualified preschool head, and met requirements for fees paid by parents. ${ }^{11}$

To receive a subsidy, an approved preschool had to satisfy four main requirements. The preschool had to: (1) have staff and/or a board of members with expertise on children; (2) be open for at least four hours each working day; (3) provide services exclusively or predominantly to children from poor families; and (4) charge fees that could cover the meals provided to children (very poor parents could apply for an exemption). ${ }^{12}$

In addition, regulations regarding the educational requirements for preschool staff, their wages, and the child-to-teacher ratio were put in place in the early 1930s. ${ }^{13}$ Preschool staff were trained to teach pedagogical content inspired by the principles of influential educators such as Friedrich Fröbel and Maria Montessori, with an emphasis on providing a stimulating environment for children. The government also regulated and monitored preschools' hygienic conditions, and encouraged them to work together with local physicians and dentists to monitor children's health, reimbursing expenses related to these health check-ups.

In sum, government-regulated formal preschools likely provided poor Danish children aged 3-7 with a higher quality of care, early education, nutrition, and health services than they would have otherwise received. During this time period, poor mothers who had to work would typically leave small children alone at home, under the supervision of older siblings,

\footnotetext{
${ }^{10}$ Subsidies ranged between 30 and 50 percent for expenses related to daily operations, and were around 50 percent for expenses related to the establishment or improvement/expansion of existing institutions. From 1951 onwards, both the national and municipal governments were involved in the financing of preschools. If a municipality ran a preschool or subsidized at least 30 percent of its expenses, the subsidy from the national government was raised to 40 percent.

${ }^{11}$ Fees were between 3 Danish crowns per week in the 1930s and 8-10 Danish crowns per week in the 1950 s. They covered the food and milk that was provided to children at most preschools.

${ }^{12} \mathrm{~A}$ preschool could either be run by a municipality (which employed staff with expertise on children) or be run by a private organization with a board of members with expertise on children (e.g., a pediatrician, a teacher, etc.). Preschools were allowed to be closed for up to four weeks during the summer and a total of two weeks around holidays such as Christmas or Easter. Finally, the requirement for serving children from poor families was loosened over time-beginning in the late 1940s, preschools that did not predominantly serve poor families could also receive smaller subsidies from the national and municipal governments (for a total of around 35 percent of all costs) (Skjernbæk, various years).

${ }^{13}$ Trade unions that focused on pedagogical work - and lobbied for adequate educational programs and higher wages for the preschool staff-were established as well.
} 
or in the care of other relatives or neighbors (Pedersen et al., 2011, p728).

\subsection{Nurse Home Visiting in Denmark}

In 1937, the Danish parliament passed a bill that regulated the content and funding of a NHV program serving all families with newborns. The Danish National Board of Health (DNBH) had developed the program to address the relatively high infant mortality rate of around 6.5 percent at the time (DNBH, various years). As a considerable share of infant mortality was due to preventable causes - among them, infectious diseases caused by the improper treatment of cows' milk - the DNBH designed the program to promote breastfeeding and a proper home environment. Approved and trained nurses were assigned to visit newborns and their mothers approximately 10 times in the first year of life and teach mothers about the basics of infant care, as perceived at the time: "calmness, orderliness, and cleanliness". Nurses monitored infants' development and referred ill infants to doctors for treatment (for more details on the program see DNBH, 1970; Buus, 2001; Wüst, 2012; Hjort et al., 2014).

While DNBH centrally designed the program and the Danish government co-funded it, implementation was under municipal discretion. To implement NHV and be eligible for a 50 percent refund of program expenses from the government, municipalities had to find trained nurses and get approval for their implementation plan from the DNBH. Variation in the timing of program implementation across municipalities from 1937 onwards largely stemmed from the lengthy accreditation process at the DNBH. Another source of variation came from differences in the preferences of local general practitioners, who in some places promoted the initiation of NHV but in other places opposed it as it was undermining their authority (Buus, 2001).

\subsection{Related Literature}

Preschool programs. The existing literature on the impacts of preschool programs is large, but has mostly focused on their short- and medium-term effects in childhood and young adulthood and has found mixed results. There are a number of studies that find that preschool improves short-run cognitive test scores (Loeb et al., 2007; Gormley and Gayer, 2005; Fitzpatrick, 2008; Berlinski et al., 2009). Similarly, evaluations of Head Start- 
the largest U.S. federal program offering preschool education to low-income children - find positive short-term impacts on test scores, concentrated among the most disadvantaged children (Office of Planning, Research, and Evaluation, 2010; Bitler et al., 2014). However, other papers suggest that short-term impacts of preschool dissipate by the end of first grade (Magnuson et al., 2007; Office of Planning, Research, and Evaluation, 2010), while still others find no or even adverse impacts of preschool exposure on cognitive and non-cognitive child development (Baker et al., 2008; Herbst and Tekin, 2010; Datta Gupta and Simonsen, 2010; Baker et al., 2015). Overall, the mixed results imply that program quality and the availability and quality of alternative options are likely important determinants of program success.

Despite the mixed evidence on short-run impacts of preschool, the research points to positive medium-term effects of some programs that specifically target disadvantaged children. For example, children who attended Head Start are less likely to be placed in special education or retained in a grade, are more likely to graduate high school and attend college, have higher earnings in their 20s, and are less likely to be booked or charged with a crime than their non-Head-Start-exposed siblings (Currie and Thomas, 1995; Garces et al., 2002; Deming, 2009). Head Start may also reduce childhood mortality (Ludwig and Miller, 2007). Smaller-scale intensive targeted preschool interventions such as the Perry Preschool Program and the Abecedarian Project have even larger positive impacts on medium-run outcomes (Schweinhart et al., 2005; Belfield et al., 2006; Anderson, 2008; Heckman et al., 2010; Masse and Barnett, 2002; Campbell et al., 2014). ${ }^{14}$

In Scandinavia, the evidence on the impacts of preschool (often referred to as "childcare" in this literature) on outcomes through age 30 comes from recent expansions in universal programs offered to children across all socio-economic groups. ${ }^{15}$ In Norway, Havnes and Mogstad (2011) study an expansion of universal preschool in the 1970s and find positive impacts on educational attainment and labor market participation, while Havnes and Mogstad

\footnotetext{
${ }^{14}$ There is also some evidence that low-quality programs have negative effects on non-cognitive outcomes in the medium-term, in terms of health, life satisfaction, and crime (Baker et al., 2015).

${ }^{15}$ There is also some evidence that universal preschool programs in Georgia and Oklahoma have positive impacts on low-income children's test scores in 4th and 8th grade, but no impacts on the achievement of higher-income children (Fitzpatrick, 2008; Cascio and Schanzenbach, 2013). Additionally, Cascio (2009) finds that the introduction of kindergardens into U.S. public schools reduced the high school dropout rate, but had no impacts on other outcomes such as employment, college attendance, and earnings.
} 
(2015) show that the benefits of this program are concentrated among the least advantaged individuals. In Denmark, Bingley et al. (2015) use variation in preschool openings from the same time period to instrument for maternal employment, and find large positive impacts on children's schooling and adult earnings. Examining even more recent cohorts, Datta Gupta and Simonsen (2016) find positive medium-run effects of Danish preschools on children's test scores in ninth grade.

Our study provides the first evidence on the persistence of impacts of access to a high quality targeted preschool on educational, labor market, and health outcomes through age 65 and on the education of the next generation.

NHV. In addition, we examine how the added value of preschool varies with exposure to an earlier health intervention. A separate literature has established mixed effects for home visiting programs. In the U.S., several programs have been evaluated using experimental designs. Results indicate that the success of these programs depends on the level of program intensity (i.e., frequency of visits, curriculum breadth, etc.) and on the professional qualifications of the home visitors (i.e., local community members versus professional trained nurses). ${ }^{16}$

Wüst (2012) and Hjort et al. (2014) have studied the short- and long-term impacts of the Danish NHV program that we examine here. ${ }^{17}$ Wüst (2012) finds that access to NHV led to a significant increase in infant survival of about 5-8 lives saved per 1000 live births. NHV accounted for about 17-29 percent of the overall decreases in diarrhea-related mortality over this time period in Denmark. These results suggest that the program worked in the intended ways, and the survivors of treated cohorts likely experienced fewer severe illnesses and enjoyed better nutrition. Hjort et al. (2014) document that the positive health effects persist into adulthood - individuals who were exposed to NHV at birth are less likely to die at ages 45-57. Further, they show that treated individuals are less likely to be diagnosed

\footnotetext{
${ }^{16}$ For example, see St. Pierre and Layzer (1999) for evidence on the Comprehensive Child Development Program (CCDP); Harding et al. (2007) for a review of the literature on the Healthy Families America (HFA) program; and Olds (2006) for results on the Nurse Home Visiting Parternship (NHVP) program.

${ }^{17}$ Ongoing work is studying the long-term effects of similar programs in Sweden and Norway. Bhalotra et al. (2015) show that the Swedish program substantially reduced mortality through age 75 , while Bütikofer et al. (2014) document that the Norwegian program had lasting positive effects on education and adult earnings.
} 
with cardiovascular diseases and are admitted for fewer hospital nights in the same age range. These findings are in line with other research that has documented the long-run benefits of improving early-life health and nutrition for reducing later life incidence of cardiovascular diseases (Forsdahl, 1979; Barker, 1990; Bhalotra and Venkataramani, 2012; Hoynes et al., 2016). ${ }^{18}$

Evidence on interactions. Our analysis of interactions between two different types of interventions at adjacent developmental stages (i.e., during infancy and between the ages of 3 and 7) is in part motivated by the work of James Heckman and his co-authors, who developed a model that extends the seminal model of Becker and Tomes (1986) on parental investments in human capital (see, e.g.: Cunha and Heckman, 2007; Heckman and Masterov, 2007; Cunha et al., 2010). A key feature of the model is the idea of dynamic complementarities, where human capital and investments in one period raise the productivity of investments in a future period.

Causal empirical evidence on complementarities between investments is scarce. One set of studies, arguing in favor of complementarities, shows that the effects of preschool interventions are larger for those with higher measures of initial endownments. For example, Heckman et al. (2013) find that the Perry Preschool program had the largest impacts on cognitive achievement among children at the top of the distribution, while Aizer and Cunha (2012) show that children with higher measures of cognitive development at eight months experience the largest gains in IQ as a result of Head Start participation. ${ }^{19}$

At the same time, another set of studies finds that the benefits of preschools are largest for the least advantaged children, which is more consistent with different investments serving

\footnotetext{
${ }^{18}$ Hjort et al. (2014) also consider the long-run effects on educational and labor market outcomes, finding less consistent and much smaller effects.

${ }^{19}$ A related strand of literature studies the relationship between initial endowments of children and subsequent parental investments. These studies do not estimate the interaction effects between investments and endowments on long-run outcomes, but rather ask whether parents invest in a reinforcing or compensating manner. Adhvaryu and Nyshadham (2014) find evidence of reinforcing investments, showing that children exposed to an iodine supplementation program in Tanzania are more likely to receive vaccinations and are breastfed longer. Bharadwaj et al. (2013) use data from Chile and Norway and find no differences in parental responses between children who are more or less likely to receive medical intervention at birth. In contrast, Sievertsen and Wüst (2015) show that in Denmark parents do respond to medical interventions at birthmothers who are discharged from the hospital on the day of giving birth are less likely to breastfeed at four months than mothers who are discharged at a later time. See also Almond and Mazumder (2013) for a review.
} 
as substitutes. Using quantile regression methods, Bitler et al. (2014) show that the effects of Head Start on test scores are concentrated among students at the bottom of the distribution, while Havnes and Mogstad (2015) show that the benefits of Norwegian universal preschool are concentrated in the lower and middle parts of the earnings distribution. Similarly, Havnes and Mogstad (2011) find that the positive effects of Norwegian preschool are greater for children with less educated mothers than for children with higher educated mothers. ${ }^{20}$

Yet since variation in initial human capital and socio-economic status is not random, unobservable sources of heterogeneity could contribute to differences in the returns to preschool across children. We address this challenge by examining the interaction between preschool and another independent program targeting health in their first year of life. In other words, we study whether the impact of preschool exposure is different across individuals who quasiexogenously differ in terms of their early-life environments. While our analysis is limited in that we can only observe the reduced form effects of the two interventions and have no data on initial conditions or parental responses, we advance the existing literature by overlaying two sources of program variation that allow us to causally identify interaction effects. Moreover, since many existing early intervention programs have similar target groups and eligibility criteria, evidence on interaction effects across programs is instrumental for efficient policy design.

We are aware of only a handful of recent working papers that take similar approaches. Bhalotra and Venkataramani (2012) overlay state-year variation in access to sulfa drugs (antibiotics used to treat pneumonia) in the 1930s with variation in several measures of racial segregation. They show that African-American cohorts born in the U.S. in the 1930s experienced higher human capital gains from access to sulfa drugs when they faced less segregation, better schooling, and overall opportunity for social mobility.

Malamud et al. (2015) combine variation from an abortion reform and a regression discontinuity design in school quality in Romania to study whether cohorts born after abortion

\footnotetext{
${ }^{20}$ Several studies on other interventions have also found the largest benefits for the least advantaged individuals: Meyer and Wherry (2012) document that early-life access to Medicaid reduced the mortality rates of black but not white teens; Carneiro et al. (2011) show that the long-run effects of maternity leave are largest for children with low educated mothers; Dahl and Lochner (2012) find that the positive impacts of income from the Earned Income Tax Credit (EITC) are largest for children from disadvantaged families. More generally, Løken et al. (2012) find that the marginal impacts of family income are largest at the bottom of the income distribution.
} 
was made legal (who likely experienced higher parental investments) benefitted more from school quality than cohorts born before. They estimate negative interactions between the reform and school quality, although not all are statistically significant.

The other two concurrent papers on this topic find stronger evidence of negative interaction effects. Gunnsteinsson et al. (2014) study an interaction between a tornado and a randomized vitamin supplementation program in Bangladesh, and show that infants who received vitamin supplementation at birth were protected from the negative effects of exposure to the tornado in utero in terms of their morbidity and anthropometric measures at ages 0-6 months. Adhvaryu et al. (2015) analyze an interaction between rainfall shocks and conditional cash transfers under the Progresa experiment in Mexico, showing that the transfers can mitigate about 80 percent of the adverse effect of rainfall on later educational attainment.

\section{Data and Sample}

We merge data from several sources. First, we use information on the geographical and administrative structure of Denmark 1920-1955 to assign treatment status to individuals. Second, we collect data on the expansion and approval of preschools and the implementation of NHV. Third, we compile a set of historical municipality control variables. Fourth, we use administrative individual-level data on adult outcomes for cohorts born in 1930-1957 and their children.

Data on Denmark's historical administrative structure. We use data from the "DigDag" project (Digital Atlas of the Danish Historical and Administrative Geography) that provides a link across several historical Danish administrative entities, including parishes and municipalities. ${ }^{21}$ As all births in Denmark are registered at the parish level, we use the "DigDag" data together with information on individuals' parishes of birth in our long-run

\footnotetext{
${ }^{21}$ For more information, please see: www.digdag.dk. In the period that we study, Denmark consisted of over 1,300 municipalities that were heterogeneous in their size, population density, and composition. Each municipality contained one or more parishes. The vast majority of rural municipalities only had one parish each. The approximately 86 urban municipalities - also known as "Købstceder," or market towns - consisted of multiple parishes.
} 
outcomes data to merge individuals to their municipalities of birth (and thus to assign individuals' treatment status).

Data on preschool centers. We have collected information on all approved Danish preschool centers for children aged 3-7 years that existed over the 1921-1960 period from nine books published in 1921, 1924, 1927, 1936, 1942, 1946, 1950, 1956 and 1960 (Skjernbæk, various years). ${ }^{22}$ These data contain information on the preschool's first registered exact address, the year of establishment and the year of approval, and the number of children registered in each of the given nine years. ${ }^{23}$ We use the address data to match preschools to municipalities.

Although our data have information on both the year of establishment and the year of approval for each preschool, we use variation in the timing of government approval. Approval entails a uniform and regulated treatment that leads to a substantial improvement in preschool quality, and we therefore focus on the effects of access to a formally approved preschool. ${ }^{24}$

Out of the 1,354 Danish municipalities that existed between 1930 and 1960, 140 had at least one approved preschool by 1960. Figure 1 depicts these municipalities in a map of Denmark (using its 1950 administrative structure). As we show in Table 1, the municipalities without approved preschools are mostly very small and rural; the 140 municipalities with at least one approved preschool had ten times higher average population counts in 1930 than the other municipalities. Thus individuals born in municipalities with at least one approved preschool account for 53 percent of the population we observe in our administrative individual-level data (described below). Table 1 also shows that there are substantial differences between the municipalities with and without approved preschools by 1960 in terms of politics, average income, and industrialization. Therefore, we limit all of our analysis to the

\footnotetext{
${ }^{22}$ The majority of preschools served children between ages 3 and 7 . A minority of preschools in our data also accepted younger children.

${ }^{23}$ We use the original address of the preschool even though some preschools move. Usually, preschools only moved within the same municipality, e.g., to get more space. The records for the total number of slots per preschool are unfortunately incomplete; we only have data on the number of enrolled children in each preschool in the given nine years.

${ }^{24}$ In practice, the years of establishment and approval are the same for many preschools. Some preschools that were originally established as unregulated obtained approval in a later year. Our results are similar if we use the year of establishment to assign treatment (and available upon request).
} 
relatively homogeneous sample of 140 municipalities that ever had a government-approved preschool by 1960. These 140 municipalities are still fairly small entities, with a median population of 4,606 in 1930.

Figure 2 shows the evolution of preschools in these 140 municipalities. ${ }^{25}$ In 1933, only about 20 percent of municipalities in our sample had at least one approved preschool, whereas by 1960, all of them did. Most municipalities only ever have one approved preschool - the median number of preschools per municipality is one, while the 75th percentile is two. Only 18 municipalities in our data ever had more than five approved preschools. Thus, most of our analysis uses variation in the initial preschool approval (changing from zero to one approved preschool).

Data on the NHV program. We use information on the date of NHV program approval from the DNBH in the period 1937-1949 from records stored in the Danish National Archives. ${ }^{26}$ We also obtained aggregate data from Skjernbæk (various years), which contain lists of NHV-treated municipalities. For municipalities that did not implement an NHV program by 1949, we assign a (somewhat less precise) treatment date using these lists. ${ }^{27}$

Approval was only granted to municipalities with sufficient coverage, i.e., if the number of nurses matched the estimated demand (number of infants). Thus, we create an indicator for an approved program being in place. ${ }^{28}$

Appendix Figure 1 depicts the variation in preschool and NHV availability by birth year. Access to preschool is measured at age 3, while access to NHV is measured at birth. For cohorts born in 1930, about 80 percent of municipalities did not provide preschool and NHV was not yet established. As the preschool and NHV programs expanded, the percentage

\footnotetext{
${ }^{25}$ We begin the graph in 1933 as our oldest cohorts are born in 1930 and we measure preschool exposure at age 3 .

${ }^{26}$ Program approval date indicates the date starting with which municipalities were eligible for a $50 \%$ state refund for program expenses (for further details see Hjort et al., 2014).

${ }^{27}$ Out of our 140 analysis municipalities, 28 do not implement an NHV program by 1949 . We assign either (i) the year of the previous publication to municipalities that are listed as treated in a given publication or (ii) a "never treated" status for municipalities that are not featured on the lists. We test the robustness of our main results to dropping cohorts born after 1949 in these 28 municipalities with less precise NHV treatment dates.

${ }^{28}$ The archive data on the number of nurses is incomplete and of poor quality. Moreover, we assume that NHV program implementation is "an absorbing state". The vast majority of municipalities have the NHV program in place continuously once it was implemented.
} 
of municipalities with both programs increased from zero for cohorts born in 1936 to 86 percent for cohorts born in 1957 in our sample. But, until 1948, between 20 and 50 percent of municipalities only had preschool and no NHV. In the late 1940s, nearly 10 percent of municipalities only had NHV and no preschool. In sum, during our analysis time frame, some cohorts were exposed to neither preschool nor NHV, other cohorts were exposed to either only preschool or only NHV, while still others were exposed to both programs.

Data on municipality-level demographics, live births, and infant deaths. We use municipality-level data on various control variables. Data on population are available for all municipalities from the quinquennial censuses. The data on other controls come from the Statistical Commune Data Archive (Danish Data Archive), and contain information on municipal characteristics such as the share of left-wing voters at several national and local elections, the share of females, the share of workers in the industrial sector, and the share of property tax payers. As we only have control variables for a subset of our sample years (election and census years), we interpolate these data for some of our analyses. ${ }^{29}$

Additionally, we use data on the annual number of live births and infant deaths for the 86 urban municipalities for years 1933-1950 (DNBH, 1933-1950). These data are unfortunately not available for the (much smaller) rural municipalities during this time period. In the urban municipalities, the median number of live births over 1933-1950 was 146.

Individual-level administrative data on outcomes of the first generation. We use administrative data on outcomes available for years 1980-2012/2013. We study a variety of outcomes observed at different ages for our cohorts. First, we construct three measures of educational attainment: years of schooling, and indicators for basic education (nine years of compulsory schooling only) and higher education (more than compulsory).

Second, we examine several labor market and income variables. Our main specifications focus on outcomes measured around age 50; at this age, individuals are well established in their careers and we can observe all of our cohorts in the outcome data. We consider log total income, log wage income, an indicator for any wage income, and an indicator for

\footnotetext{
${ }^{29}$ Where necessary (e.g., data on votes), we constrain our linear interpolation to values in the 0-100 range.
} 
having a blue-collar occupation. For each of the income variables, we calculate individuallevel three-year moving averages (i.e., an average over ages 49-51) before taking logs. The indicator for any wage income similarly refers to any positive income in the three-year age range. We study labor market outcomes averaged for each individual over a set of ages rather than outcomes measured at a particular age (e.g., age 50) in order to minimize any residual variance or measurement error in the observed employment and earnings distributions and to ameliorate concerns that any effects we see are driven by a contemporaneous shock in any particular earnings year.

Third, we study survival beyond age 65. For this outcome, we left-censor the data such that all individuals in our analysis sample enter the risk period that we consider at age $50 .{ }^{30}$ Additionally, we study the probability of being diagnosed with one of the following conditions by age 60: cardiovascular conditions, heart disease, diabetes, and cancer. Data on diagnoses come from hospital records available over 1980-2012. ${ }^{31}$

Individual-level administrative data on outcomes of the second generation. We have data on the fertility of women born in 1935-1957 in our sample. ${ }^{32}$ We examine several fertility outcomes for the women in the 1935-1957 cohorts - an indicator for no children, total number of children, maternal age at first birth, and an indicator for the father's information being missing.

We then link all mothers in our sample to their oldest children, for whom we can observe educational outcomes at age 25. In the second generation, we can observe years of schooling, an indicator for basic education, an indicator for gymnasium education (academic high school after the nine years of compulsory education), and an indicator for higher education. Given that the average age at graduation from university is in the late 20s in Denmark, we lack

\footnotetext{
${ }^{30}$ Since our outcomes data begin in 1980 , individuals enter our sample at different ages. As such, our oldest cohorts must have survived to age 50 to be observed in the data, while our youngest cohorts must have only survived to age 23 . When studying survival, we limit our analysis to only those individuals who have survived to at least age 50. The resulting sample is right-censored, but this type of censoring is taken into account by our cohort fixed effects.

${ }^{31}$ For the period 1980-1993, we only have information on diagnoses for patients who are admitted as inpatients. From 1994 onwards we also observe outpatient diagnoses.

${ }^{32}$ In the Danish register data, it is possible to link all cohorts born in 1960 and later to their parents (Pedersen et al., 2006). Unfortunately, we cannot link treated children to their families; i.e., we cannot examine whether access to preschool or NHV impacted the fertility patterns of the mothers of treated children.
} 
power to examine this last margin of the educational distribution.

Sample construction and selection. We limit our sample to individuals born in Denmark between 1930 and 1957. In addition, to be a part of our analysis, individuals have to meet two criteria: (1) the individual must have a valid code for his/her parish of birth that allows us to assign treatment status; and (2) the individual must be observed in our post-1980 outcome data.

As Appendix Figure 2 shows, we can match around 90 percent of Danish-born individuals in our outcome data to a parish of birth. Older cohorts are less likely to be matched to valid parish codes. ${ }^{33}$

Since we can only study the outcomes of survivors who are observed in the register datai.e., those who were aged 23-50 in 1980 - we are concerned with endogenous sample selection due to effects on mortality or emigration before 1980. We address this concern in two ways. First, we compare our analysis sample to annual aggregate data on live births and infant deaths in Denmark. Appendix Figure 3 illustrates the percentage of "missing" Danish-born individuals in our outcome data (including individuals with no valid parish code). ${ }^{34}$ The figure indicates that 4-13 percent of Danish-born individuals are missing in the post-1980 data due to mortality or emigration, and that we miss - as expected-more individuals from older cohorts. ${ }^{35}$ However, using only the younger cohorts with fewer missing observations, we show that statistically significant mortality impacts only materialize around age 60 for women (and not at all for men) (see Appendix Figure 4). Thus we do not believe that selection due to mortality prior to age 50 has a meaningful impact on our results.

Second, we use our municipality-level data on live births and infant deaths for 86 urban municipalities for years 1933-1950. We correlate the share of "not missing" Danish-born

\footnotetext{
${ }^{33} \mathrm{We}$ omit the following groups with invalid parishes: individuals with errors in their parish of birth registration (such as those who are registered using post-1970 municipality information that cannot be matched to the pre-1970 municipal structure), individuals who were registered by religious minorities such as Catholics, and individuals with undocumented parish codes. Also, individuals who were born in hospitals cannot be merged to their municipalities of birth, and they are omitted from our sample as well. Hospital births for these cohorts were very rare - only 5.5 percent of our sample - as home births were the norm in Denmark up until the 1960s.

${ }^{34}$ We calculate this percentage as: (\# of Danish-born observations in register data)/(\# of live births - \# infant deaths). Aggregate data on live births and infant deaths come from DNBH (various years).

${ }^{35}$ Hjort et al. (2014) present a similar table in their analysis of the long-run effects of NHV. It also supports the finding that a relatively low and stable number of individuals are missing from the post-1980 data.
} 
individuals in our outcome data relative to all first-year survivors with our key treatment variable, an indicator for an approved preschool in the municipality $\times$ year. Appendix Table 1 reports the results from various specifications of this regression, showing no statistically significant relationships.

Our analysis sample of Danish-born individuals with valid parish codes consists of 1, 657,399 observations. When we limit to individuals born in the 140 municipalities with an approved preschool center by 1960, we are left with 879,647 observations.

\section{Empirical Methods}

Our analysis exploits the municipality $\times$ year variation in preschool approvals (and the NHV rollout) to create difference-in-difference and event-study designs. To ease the computational burden, we collapse our individual-level data into 3,918 municipality $\times$ birth-year-cells and weight by cell size. ${ }^{36}$ For some specifications, we also present results on heterogeneous effects by gender, using data at the gender $\times$ birth-municipality $\times$ birth-year level.

To analyze the effects of preschool access, we estimate versions of the following equation:

$$
Y_{y m c}=\alpha_{0}+\alpha_{1} \text { PreschoolAge } 3_{y m}+\lambda_{m}+\gamma_{y}+\nu_{c} \times y+\epsilon_{y m c}
$$

for cohorts born in year $y$, municipality $m$, and county $c .{ }^{37} Y_{y m c}$ is an outcome of interest such as education or adult income. Preschool Age $3_{y m}$ is an indicator equal to one for cohorts that had at least one approved preschool in their municipality of birth at age 3, and zero otherwise. $^{38} \lambda_{m}$ are municipality fixed effects, while $\gamma_{y}$ are year of birth fixed effects. We also add county-specific linear time trends denoted by $\nu_{c} \times y \cdot{ }^{39} \epsilon_{y m c}$ is the error term, which we cluster by municipality. The key coefficient of interest, $\alpha_{1}$, identifies the effect of having a government-approved preschool center in one's municipality of birth at age 3 on the outcome

\footnotetext{
${ }^{36}$ This method is equivalent to estimating the corresponding individual-level regressions with no individuallevel controls.

${ }^{37}$ Counties are the next-largest geographical entities after municipalities. In our sample of 140 municipalities, there are 23 counties and the capital Copenhagen, which had special status in the county structure (i.e., was a separate administrative entity). Counties contain between two and eight municipalities.

${ }^{38}$ These analyses implicitly assume that the municipality of birth is also the municipality of residence during early childhood.

${ }^{39}$ We test the robustness of our results to the exclusion of county time trends and to the inclusion of interpolated municipality characteristics and municipality-specific pre-trends, as described further below.
} 
of interest.

We also estimate event-study regressions to analyze the effects of preschool access by age of exposure:

$$
\begin{gathered}
Y_{y m c}=\kappa_{0}+\sum_{a=0}^{a=6} \tau^{a} \text { Preschool }_{y m}^{a}+\sum_{a=8}^{a=11} \tau^{a} \text { PreSchool }_{y m}^{a}+\text { BornAfter }_{y m}+\text { Older }_{y m} \\
+\lambda_{m}+\gamma_{y}+\nu_{c} \times y+\epsilon_{y m c}
\end{gathered}
$$

Here, Preschool ${ }_{y m}^{a}$ is an indicator equal to one for cohorts that were age $a$ in the year of the first preschool approval in their municipality of birth and zero otherwise. We include indicators for ages 0 to 6 and 8 to 11 (with age 7, the oldest age at which a child could attend preschool, as the omitted category). BornAfter Bm $_{\text {is }}$ an indicator for cohorts born after the preschool approval (i.e., they were aged less than 0 at the time of approval), while Older $_{y m}$ is an indicator for cohorts who were older than age 11 at the time of approval. The remainder of the variables is the same as in equation (1). The event-study specification allows us to test for differences in effects by the number of potential years of exposure: cohorts who were aged 3 or less at the time of approval could attend formal preschool for five years until age 7, while cohorts who were older could only attend for fewer years, or none at all. Moreover, this regression contains a placebo test as we can check whether preschool access is correlated with the outcomes of cohorts who were too old at the time of preschool approval.

To examine interactions between preschool and NHV, we estimate:

$$
\begin{gathered}
Y_{y m c}=\beta_{0}+\beta_{1} \text { PreschoolAge } 3_{y m}+\beta_{2} N H V_{y m}+\beta_{3} \text { PreschoolAge } 3_{y m} \times N H V_{y m} \\
+\lambda_{m}+\gamma_{y}+\nu_{c} \times y+\epsilon_{y m c}
\end{gathered}
$$

Here, $N H V_{y m}$ is an indicator equal to one for cohorts that had the NHV program in their municipality in their year of birth and zero otherwise. All of the other variables and coefficients are the same as in equation (1). $\beta_{1}$ measures the impact of access to preschool at age 3 for cohorts without NHV, while $\beta_{2}$ measures the impact of access to NHV at birth for cohorts without preschool at age $3 . \beta_{3}$ identifies the interaction effect between the two 
programs.

Identifying assumptions. Our empirical strategy yields estimates of the causal effects of early access to a high quality preschool and the interaction effects between access to preschool and NHV under the assumptions that: (1) the timing of preschool approvals is uncorrelated with other municipality time-varying characteristics that also predict our longrun and intergenerational outcomes of interest; and (2) the timing of preschool approvals is uncorrelated with the NHV program rollout. ${ }^{40}$

With regard to assumption (1), our estimation approach addresses several concerns: Our year-of-birth fixed effects control for overall trends in cohort and intergenerational outcomes, while the municipality fixed effects control for all time-invariant differences between municipalities. Further, our county linear trends allow for the outcomes of cohorts born in each of the 24 counties in our data to follow distinct trends.

The period that we study calls for a discussion of the role of World War II and its possible influence on our sources of variation. This influence would be a concern if it varied across municipalities, and was therefore not accounted for by our cohort fixed effects. Historical accounts make clear that Denmark - unlike many other European countries - was not very severely impacted by the German occupation between 1940 and 1945. As noted in several publications, cooperation with the German forces with respect to political and economic decisions during the war resulted in a minimal impact of the occupation (Pedersen, 2009; Poulsen, 2002). While coffee, tobacco and other goods were rationed, there was nevertheless a stable supply of food for all Danish citizens (e.g., milk and bread were not rationed, see Poulsen, 2002). According to Pedersen (2009), "among all occupied countries, Denmark was the country with the smallest decrease in the standard of living and the country where everyday life was least impacted." (authors' translation, p. 404 in Pedersen, 2009). As such, we do not believe that World War II is a confounding factor for our analysis. Moreover, we find no evidence of disruptions in the spread of preschools or NHV during the war years.

Additionally, while the first identifying assumption remains inherently untestable, we

\footnotetext{
${ }^{40}$ We also need for the timing of the NHV program rollout to be quasi-exogenous and uncorrelated with municipality time-varying characteristics. Evidence on this point has been provided by Wüst (2012) and Hjort et al. (2014).
} 
conduct some indirect tests to evaluate its plausibility. Specifically, we estimate versions of model (1) using interpolated municipality characteristics as outcome variables to test for a correlation between the timing of preschool approvals and other time-varying municipalityspecific factors. Table 2 presents the results, which show that preschool approval is positively correlated with the percent of the population that is urban, and negatively correlated with the percent of the population that is agricultural and the percentage of property tax payers. These associations imply that preschool approvals occurred in urban areas earlier than in rural areas on average (rural areas are more likely to have property tax payers). When we include linear trends interacted with an urban/rural municipality indicator in these specifications in Appendix Table 2, the correlations become insignificant at the 5\% level. To address this issue further, we also show that our main results are robust to: (a) including urban/rural municipality indicators interacted with linear trends, (b) including municipality fixed effects interacted with linear pre-trends, and (c) including all of the interpolated municipality characteristics presented in Table 1 as control variables. See Section 5 for more details. $^{41}$

We can directly test the second identifying assumption with our data. In Table 3, we present results from correlating preschool access with access to NHV. Specifically, in column (1), we estimate a version of equation (1), using an indicator for having the NHV program at birth as the dependent variable. In column (2), we instead regress an indicator for having access to a preschool at age 3 on an indicator for having access to the NHV program at birth. In both specifications, we find little evidence for any statistically significant (or economically meaningful) relationship between the two programs.

\section{Results}

\subsection{Long-Run Effects of Preschool on the First Generation}

We begin with results on the long-term impacts of access to preschool for the first generation. Table 4 presents results from estimating versions of equation (1) using the following outcomes

\footnotetext{
${ }^{41}$ Another source of potentially confounding variation is a schooling reform in 1958, which increased access to academic-track high schools for rural students. We show that our results are robust to controlling for this reform in Section 5 .
} 
as dependent variables: years of schooling at age 50, an indicator for basic education at age 50, log mean total income between ages 49 and 51, and an indicator for survival beyond age 65.

We show results from four different specifications. In the first column, we present a baseline model with only municipality and birth year fixed effects. In column (2), we also include county linear time trends. In column (3), we add in all of the available interpolated municipality characteristics as time-varying controls. Finally, column (4) includes municipality-specific linear pre-trends instead of the county linear trends. We use municipality trends based on the pre-treatment data only because our treatment effects likely consist of changes in both outcome levels and trends. First, take-up of preschool might increase gradually after the first center approval, meaning that cohorts born several years after a center is approved experience greater benefits than cohorts exposed to preschool immediately after the approval. Second, there may be a linear effect of each additional year of exposure between ages 3 and 7. As a result, municipality-specific time trends that use both pre- and post-treatment data will "over-control" and absorb an important part of the treatment effect we are trying to estimate.

Across all four outcomes, we see evidence that preschool improves long-term well-being. In columns (1), (2), and (4), the coefficients are all of the same sign and similar magnitude. For instance, in column (2), we find that, relative to the comparison cohorts, individuals who had an approved preschool in their municipality of birth by age 3 have 0.19 more years of schooling (1.6 percent at the sample mean), are 2.9 percentage points (9.7 percent) less likely to only have a basic education, have 1.5 percent higher income, and are 0.5 percentage points (0.6 percent) more likely to survive beyond age 65 . In column (3) - where we include the interpolated municipality controls - the coefficients are qualitatively similar to those in the other columns, but reduced in magnitude for some of the outcomes. One potential explanation for this reduction in effect size is that some of the municipality-level variables observed after preschool approval could actually be endogenous - for example, the presence of a formal preschool could affect voting behavior or average incomes (since women may be more likely to work). As such, we take the model in column (2) as our preferred specification for much of the subsequent analysis. 
Figures 3 and 4 present the corresponding event-study graphs for years of schooling and basic education, respectively. We plot the $\tau^{a}$ coefficient estimates from equation (2) and the corresponding $95 \%$ confidence intervals. Both figures show a marked improvement in educational attainment for cohorts aged 0 to 3 at the time of preschool approval. The magnitudes of the coefficients for individuals aged 4 to 6 in the year of preschool approval are smaller and consistent with a possibly linear effect of each additional year of preschool exposure. Importantly, the coefficients on exposure at ages 8 to 11 are statistically insignificant, suggesting that there are no pre-existing trends in the outcomes of cohorts who were too old to attend preschool.

Table 5 explores the effects of preschool on other labor market outcomes using the same four specifications as in Table 4 . In column (2), we see a marginally significant 1.5 percent increase in log wage income. We find no statistically significant effects on the likelihood of having any wage income or on the likelihood of having a blue-collar occupation.

When we split our sample by gender in Tables 6 and 7, we see that the income and labor market effects are driven entirely by males, while the survival effect is driven by females. The educational effects, by contrast, are similarly strong for both males and females. Men who are exposed to preschool at age 3 have 2.4 percent higher incomes at age 50, while women with preschool access are 0.8 percent more likely to survive beyond age 65 . Figures 5 and 6 plot the corresponding event-study figures for male income and female survival, respectively. Again, we see an improvement in outcomes for cohorts who were aged 0 to 3 at the time of preschool approval, and no evidence of pre-trends for cohorts older than age 7 in the year of preschool approval. We should note, however, that the individual age coefficients are less precisely estimated in these figures than those in the figures for educational outcomes, perhaps because of reduced power when we limit the sample to only one gender.

To shed light on the potential mechanisms behind the mortality effect, we examine impacts on health diagnoses separately by gender in Table 8. For women, our results suggest that preschool access may reduce the incidence of diagnoses for heart disease at age 60, which can perhaps explain the increased survival beyond age 65. For men, we see a reduction in cancer diagnoses. ${ }^{42}$

\footnotetext{
${ }^{42}$ We also examined diagnoses at younger ages, finding insignificant effects.
} 
Robustness. Our analysis rests on an assumption that, conditional on municipality and year fixed effects and county-specific time trends, the timing of preschool approvals is exogenous to other determinants of long-run outcomes. We would face a problem, if, for example, cohorts born in municipalities with earlier approved preschools were experiencing a more positive trend in their outcomes than cohorts born in municipalities with later preschool approvals. Our event-study figures suggest that differences in outcome trends across municipalities are unlikely to bias our results - we find no evidence that cohorts who were aged 8 to 11 at the time of the first preschool approval experienced any changes in their outcomes, despite the fact that slightly younger children in those same municipalities did benefit from preschool access. We have also shown that our results are mostly robust to the inclusion of different controls for trends - county linear trends, municipality-specific pre-trends, and municipality time-varying controls. We perform a number of other specification checks to test the robustness of our results and the validity of our identification strategy in Appendix Table 3.

Column (1) presents results where we only include a balanced panel of municipalities with observations in every cohort birth-year in our data; results remain largely unchanged. In columns (2)-(5), we explore alternative specifications that deal with differences across urban and rural areas. In column (2), instead of county linear trends, we include urban/rural municipality indicators interacted with linear trends. In column (3), we include county $\times$ urban/rural indicators interacted with linear trends (i.e., we allow urban and rural municipalities within each county to follow distinct trends). In column (4), we drop Copenhagen, the largest municipality and city in Denmark. In column (5), we include an interaction between an indicator for cohorts born in 1946 or later and an indicator for a rural municipality to control for the impact of the 1958 Danish schooling reform, which increased access to academic-track high schools for rural students (for details, see Arendt, 2008). Our results are robust to all of these changes. The fact that our results are robust to allowing urban and rural areas to follow differential trends suggests that the correlations in Table 2 (which showed that urban municipalities tended to approve preschools earlier than rural ones) are not driving our main results.

Columns (6)-(8) test the robustness of our results to further sample limitations. Column 
(6) drops municipalities that had an approved preschool at the beginning of our sample period in 1933. We drop these municipalities because many of the earliest approvals took place in preschools that had been introduced by philantropic organizations, and there may be a concern that these organizations also introduced other initiatives that benefitted children (e.g., vaccination programs). Column (7) limits the analysis to cohorts born in 1930-1949, a narrower window of years surrounding the preschool variation. Column (8) only includes municipalities that ever implement an NHV program. Across all of these specifications, the results remain generally consistent with our baseline model.

Column (9) of Appendix Table 3 estimates regressions where we replace the baseline indicator treatment variable with a variable for the fraction of years a cohort was exposed to an approved preschool between the ages of 3 and $7 .{ }^{43}$ The results from this alternative specification again suggest that greater exposure to preschool improves long-run outcomes.

Finally, we have tested the robustness of our results on education, income, and mortality to different ages of follow-up between 35 and 65 (in five-year intervals). Since we do not observe all cohorts at all ages, this analysis can also shed light on whether we see similar effects across different cohorts. We see a consistent positive effect of preschool on education at all of these ages. For men, we see positive effects on income at all ages, and they are not statistically different from one another. For female survival, we find that the positive effect materializes around age 60 and not earlier. ${ }^{44}$

Magnitudes. To assess the magnitudes of our estimates, we compare our findings to two strands of literature on the effects of preschool. First, we compare our results to two studies on the impacts of universal preschool expansions in Scandinavia. Havnes and Mogstad (2011) find that access to the Norwegian preschool program increases years of schooling by 0.5 percent, and reduces the likelihood of being a "low earner" at age 35 by 3.2 percent. Bingley et al. (2015) report much larger impacts from the more recent Danish preschool expansion in the 1960s and 1970s - they find a 17 percent increase in years of schooling and a 25 percent increase in age-35 earnings.

\footnotetext{
${ }^{43}$ This variable is equal to 1 for those aged 3 and younger in the year of preschool approval; $4 / 5$ for those aged $4 ; 3 / 5$ for those aged $5 ; 2 / 5$ for those aged $6 ; 1 / 5$ for those aged 7 ; and 0 for those aged 8 and older.

${ }^{44}$ Appendix Figure 4 shows results for female survival at ages 55, 60, and 65. Results for other outcomes across different ages of follow-up are available upon request.
} 
Just as in Havnes and Mogstad (2011) and in Bingley et al. (2015), our estimates represent intent-to-treat (ITT) impacts, since we do not observe whether individuals in our outcome data actually attended preschool. However, as noted previously, the other two Scandinavian papers study expansions in universal preschool, while we study a targeted program. As such, we also calculate approximate treatment-on-the-treated (TOT) effects and relate our estimates to a second line of research on the effects of targeted preschool programs.

Our ITT estimates show a 1.6 percent increase in years of schooling, a 9.7 percent increase in having more than a basic (compulsory) education, and a 1.5 percent increase in income around age 50. To calculate TOT effects, we must estimate a preschool enrollment rate, which we can do for the 86 urban municipalities in our sample. Specifically, we use data on the number of children enrolled in each preschool in each of the nine years of book publications. We interpolate these data to get estimates of enrollments in every year and aggregate to the municipality $\times$ year level. Then, using our data on the number of first-year survivors in each of the 86 urban municipalities, we can calculate the average share of children aged 3-7 years old who were enrolled in preschool in every year between 1940 and 1950. Appendix Table 4 estimates that approximately 10 percent of all living children aged 3-7 were enrolled in preschool in the urban municipalities during this time period. This figure is in line with available aggregate numbers on preschool enrollment (DST, 2008), and reflects the targeting of government-approved preschools during our study period.

The above analysis suggests that one can scale our estimates by 10 to get approximate TOT effect sizes. Although the approximate TOT magnitudes may seem very large, it is important to highlight that they are based on the most disadvantaged children for whom we may expect the largest gains from professional care and improved nutrition in governmentregulated preschools. Furthermore, our TOT estimates are actually not out of step with the U.S. literature on participation in targeted preschool programs. For example, Garces et al. (2002) find that Head Start participation increases the likelihood of high school completion by 26 percent and raises the likelihood of college attendance by 28 percent among whites, while Schweinhart et al. (2005) report that participation in the Perry Preschool program increased the age-40 earnings of males by 30 percent and of females by 20 percent. Heckman et al. (2010) estimate a lifetime earnings impact of participation in the Perry Preschool 
program of $\$ 145,461$ for males and $\$ 211,651$ for females (in undiscounted 2006 dollars). ${ }^{45}$

\subsection{Effects of Preschool on the Second Generation}

Having shown that preschool access has large and persistent positive effects on adult wellbeing throughout the life cycle, we proceed to examine whether these benefits transmit to the next generation.

Before doing so, we first test whether preschool exposure affected the fertility behavior of women in our analysis sample. In Appendix Table 5, we present results from specifications that limit the sample to women born in 1935-1957 for whom we have complete fertility data. As outcomes, we consider: an indicator for having no children, the total number of children, the mother's age at first birth, and an indicator for the father's information being missing from any of the children's birth certificates. None of the effects is significant at the $5 \%$ level, although we do find a marginally significant 0.6 percentage point decline in the likelihood of having no children and an increase in the age at first birth by 0.08 years. These results suggest that any selection into fertility - and hence into our sample of second generation outcomes - is likely to be small.

Our analysis of second generation outcomes focuses on the oldest children of the mothers in our baseline sample. Table 9 presents results for educational outcomes measured when these children are age 25. We see positive impacts on the second generation's educational attainment-years of schooling increases by about 0.4 percent, which seems to be driven by a 6 percent reduction in the likelihood of only having a basic education and about a 3.7 percent increase in the likelihood of having a gymnasium education.

We can place our results for the second generation in the context of the literature on intergenerational transmission of socio-economic status (e.g.: Solon, 1992; Bauer and Riphahn, 2004; Lee and Solon, 2009; Black et al., 2009; Chetty et al., 2014). If preschool mostly affects the education of the second generation through an improvement of the first generation's education level, the ratio of the coefficients for the two generations can approximate an intergenerational transmission coefficient for education. Note that since not all first generation women have children, we have also estimated our first generation models on the sample of

\footnotetext{
${ }^{45}$ This estimate is based off interpolations that use earnings data collected at ages 27 and 40.
} 
mothers that we use to create our second generation sample. In our preferred specification (with county linear trends), we find that access to preschool at age 3 increases maternal years of schooling by 0.17 years. ${ }^{46}$ Combining this result with the estimated coefficient for years of schooling for the second generation (0.04) suggests a transmission coefficient of around $0.24\left(\frac{0.04}{0.17}\right) .{ }^{47}$ Thus, while the effect for the second generation is much smaller than for the first generation, our findings present novel evidence that high quality preschools have the potential to mitigate some of the intergenerational transmission of low educational attainment and socio-economic status more broadly.

\subsection{Interaction Effects Between Preschool and NHV}

Next, we analyze whether access to the NHV program in infancy - which has been shown to have significant impacts on infant and long-term health outcomes by Wüst (2012) and Hjort et al. (2014) - enhances or diminishes the positive long-term and intergenerational returns to preschool. ${ }^{48}$ While we cannot directly observe the channels through which these interaction effects may operate, there are several possible mechanisms: The NHV program likely impacted infants' exposure to disease and nutrition during the first year of life through its focus on the importance of breastfeeding and having a sanitary home environment. Governmentregulated preschools probably affected children's lives in multiple ways: Children of poor working mothers likely received higher quality care and early education than they would have in alternative care arrangements (e.g., in the care of relatives or neighbors). In addition, as described in Section 2, the preschools provided children with nutritious food and health monitoring. Further, incomes in families with access to preschool may have increased because mothers could work more. Our analysis sheds light on whether the added value of all of these aspects of preschool exposure was larger (or smaller) for children who did not receive the NHV health benefits than for children whose early health was improved by NHV.

Table 10 presents results from estimating equation (3) for our main outcomes of interest in the first generation. In these specifications, the main effects of both preschool and NHV

\footnotetext{
${ }^{46}$ The results are available upon request.

${ }^{47}$ Black et al. (2013), who study the intergenerational effects of in utero exposure to radiation in Norway, use a similar strategy to calculate an intergenerational transmission coefficient of 0.625 for male IQ.

${ }^{48}$ In results available upon request, we also show that these health effects of NHV hold in our sample of 140 municipalities that ever have an approved preschool.
} 
are statistically significant and point to substantial improvements in education, income, and the likelihood of survival for cohorts who were only exposed to either preschool or NHV. ${ }^{49}$ However, the interaction coefficients are consistently opposite-signed. For cohorts who had NHV at birth, the positive impact of access to preschool at age 3 on years of schooling is reduced by 85 percent, while the decrease in the likelihood of only having a basic education is reduced by 83 percent. The increase in adult income is lowered by a marginally significant 89 percent. When we consider survival beyond age 65, the interaction coefficient is insignificant but similarly negative.

Table 11 shows the interaction results separately for males and females. As with the main effects of preschool, the impacts on education are similar across the two genders. Again, the estimated effects on income are driven by males. Cohorts who are only exposed to preschool at age 3 benefit more from it than cohorts who are also exposed to NHV at birth.

While the magnitudes of our interaction effects may seem large, they are quite similar to two other concurrent studies in completely different contexts. In particular, Gunnsteinsson et al. (2014) show that vitamin A supplementation at birth mitigates 100 percent of the adverse impact of in utero exposure to a tornado on children's health in the first year of life in Bangladesh. Adhvaryu et al. (2015) find that cash transfers under the Progresa program in Mexico reduce the adverse effect of rainfall shocks on educational attainment by 80 percent. Our estimates, which come from an analysis of very different types of interventions in Denmark, are surprisingly comparable.

To test the robustness of the interaction analysis, Appendix Tables 6 through 10 show results from a number of specifications that vary the control variables and sample. We exclude county linear trends (Appendix Table 6), include urban/rural indicators interacted with trends (Appendix Table 7), include municipality-specific linear pre-trends (Appendix Table 8), control for all available interpolated municipality variables (Appendix Table 9), and drop post-1949 cohorts in the 28 municipalities with worse NHV program data (Appendix Table 10). While the coefficients vary slightly in magnitude and statistical significance, the overall story remains the same: There are strong positive main effects of preschool and NHV

\footnotetext{
${ }^{49}$ We should note that these estimates should not be directly compared to the main effects of either preschool or NHV in regressions without interactions, as the main effects in Table 10 are conditional on the other program not being present.
} 
on adult well-being, while the interaction effects of the two programs are negative.

An additional concern with the interaction results stems from the possible selective survival of weak infants due to NHV exposure. Wüst (2012) finds that NHV increased infant survival by 0.5-0.8 percent. If the surviving infants have worse health and are less responsive to the benefits of preschool, then our negative interaction effect may be in part driven by this change in the composition of the sample. To address this issue, we randomly drop one percent of individuals in our sample who have the lowest educational attainment (seven years or less) before collapsing the data, and estimate the interaction model on this constrained sample. Appendix Table 11 presents the results from this exercise, which are very similar to our main findings. We conclude that selective survival of NHV-exposed individuals is unlikely to explain our negative interaction effects.

Finally, Appendix Table 12 presents the interaction effects for the educational outcomes of the second generation. The main effect of preschool remains statistically significant and positive, while the interaction effects are opposite-signed (although insignificant).

Discussion of interaction effects. While our interaction results suggest that children exposed to NHV benefit less from later preschool exposure and that this relationship persists in the long-run and possibly into the next generation, alternative explanations are possible. First, since the two programs were gradually rolled out over a fairly long time period, our variation creates a setting where municipalities with later preschool approvals were more likely to also have NHV than municipalities with earlier approvals. If the treatment effect of preschool is lower in municipalities with later approvals than in municipalities with earlier approvals, the negative interaction effect may in part pick up some of this heterogeneity. In Appendix Table 13 we augment equation (1) to include an interaction term between treatment and an indicator for a municipality being a "late approver" (defined as having a first preschool approval in 1940 or later). We see no statistically significant differences between early and late approvers; if anything, the signs of the interaction coefficients suggest that the treatment effects of preschool were actually larger among municipalities with later approvals than among those with earlier approvals.

Second, since both programs were implemented at the municipality level, there may be 
concerns about "overlapping labor markets". While one might worry that NHV program implementation limited nurses' ability to work at preschools (leading to a reduction in the effectiveness of preschool), this concern is not relevant to our setting since NHV nurses were highly specialized with additional training beyond standard nurse certification. Thus NHV nurses were not in the relevant pool of preschool personnel.

Third, our estimates cannot speak to potential parental behavioral responses to these public interventions. Given that preschool reduces the costs of maternal employment, parental private investments into children may have become lower once high quality preschool became available. Moreover, if parents of children who had both NHV at birth and access to preschool at subsequent ages reduced their private investments by more than parents of children who only had one program, then our negative interaction effects may be in part driven by this response. Unfortunately, we do not have any data on parental investment behaviors and thus cannot address this possibility in our analysis.

\section{Conclusion}

Although the existing literature has largely reached a consensus on the importance of earlylife interventions, the question as to whether their effects persist over the life cycle and across generations remains open. Additionally, we know very little about the added value of a program in a population that is exposed to more than one intervention. In this paper, we shed light on these questions with (1) some of the first quasi-experimental evidence on the very long-run and intergenerational effects of a high quality preschool program, and (2) an analysis of the interaction between exposure to preschool and a health intervention in infancy.

Using historical data on the timing of preschool approvals across Danish municipalities together with administrative data on outcomes for nearly one million Danish people born between 1930 and 1957, we document strong positive long-term effects of access to a high quality targeted preschool program. Cohorts with access to preschool by age 3 have 1.6 percent more years of schooling and are 9.7 percent less likely to only have a compulsory education. For males, income around age 50 is increased by 2 percent, while females are 0.8 
percent more likely to survive beyond age 65 . We also find evidence of persistent intergenerational impacts - children of women with preschool access have 0.4 percent more years of schooling and are 6 percent less likely to only have a compulsory education.

However, when we interact preschool access at age 3 with access to the NHV program in infancy, we find that the individuals only exposed to preschool benefit more from it than individuals who were also exposed to NHV. For example, for people who had NHV at birth, the positive impact of preschool on years of schooling is reduced by 85 percent. For men, the increase in adult income is lowered by 86 percent.

Our findings imply that the marginal benefit of a high quality preschool program is substantially reduced in a population that was exposed to an earlier health intervention. This means that, in a world with limited public resources, it may be efficient to design programs that specifically target populations without prior exposure to other interventions. For instance, while many over-subscribed programs for low-income children allocate slots at random or on a "first-come, first-serve" basis, our evidence suggests that an allocation mechanism that considers (the lack of) participation in earlier programs as potentially leading to greater program benefits.

Our results also imply that a high quality preschool program can compensate for low initial health, which is important in light of the substantial disparities in infant health across socio-economic groups today in the United States (Currie, 2011; Chen et al., 2014; Aizer and Currie, 2014). Although low socio-economic status children suffer from substantial disadvantages at birth in terms of health and parental resources, our findings suggest that preschool interventions can work against some of these initial shortcomings and potentially reduce inequalities in outcomes over the life cycle and across generations.

\section{References}

Adhvaryu, A., Molina, T., Nyshadham, A. and Tamayo, J. (2015). Helping children catch up: Early life shocks and the Progresa experiment, University of Michigan, unpublished manuscript.

- and Nyshadham, A. (2014). Endowments at birth and parents' investments in children. The Economic Journal.

Aizer, A. and Cunha, F. (2012). The production of human capital in childhood: endowments, investments and fertility, Unpublished manuscript, Brown University. 
- and CurRie, J. (2014). The intergenerational transmission of inequality: Maternal disadvantage and health at birth. Science, 344 (6186), 856-861.

Almond, D. and Currie, J. (2011). Chapter 15: Human capital development before age five. In O. Ashenfelter and D. Card (eds.), Handbook of Labor Economics, Handbook of Labor Economics, vol. 4, Part 2, Elsevier, pp. 1315-1486.

- and Mazumder, B. (2013). Fetal origins and parental responses. Annual Review of Economics, 5 (1), 37-56.

Anderson, M. L. (2008). Multiple inference and gender differences in the effects of early intervention: A reevaluation of the abecedarian, perry preschool, and early training projects. Journal of the American Statistical Association, 103 (484).

ARENDT, J. (2008). In sickness and in health-till education do us part: Education effects on hospitalization. Economics of Education Review, 27 (2), 161-172.

Baker, M., Gruber, J. and Milligan, K. (2008). Universal child care, maternal labor supply, and family well-being. Journal of Political Economy, 116 (4), 709-745.

- - - and - (2015). Non-Cognitive Deficits and Young Adult Outcomes: The Long-Run Impacts of a Universal Child Care Program. Working Paper 21571, National Bureau of Economic Research.

BARker, D. J. (1990). The fetal and infant origins of adult disease. BMJ: British Medical Journal, 301 (6761), 1111.

Bauer, P. and Riphahn, R. T. (2004). Intergenerational transmission of educational attainment: Evidence from Switzerland on natives and second generation immigrants. Discussion paper, IZA.

Becker, G. S. and Tomes, N. (1986). Human capital and the rise and fall of families. Journal of Labor Economics, 4 (3), S1-S39.

Belfield, C. R., Nores, M., Barnett, S. and Schweinhart, L. (2006). The high/scope perry preschool program cost-benefit analysis using data from the age-40 followup. Journal of Human Resources, 41 (1), 162-190.

Berlinski, S., Galiani, S. and Gertler, P. (2009). The effect of pre-primary education on primary school performance. Journal of public Economics, 93 (1), 219-234.

Bhalotra, S., Karlsson, M., Nilsson, T. et al. (2015). Infant health and longevity: evidence from a historical trial in Sweden. Discussion Paper 2015-08, IZA, Institute for Social and Economic Research.

Bhalotra, S. R. and Venkataramani, A. (2012). Shadows of the captain of the men of death: Early life health interventions, human capital investments, and institutions, University of Essex, unpublished manuscript.

Bharadwaj, P., Loken, K. V. and Neilson, C. (2013). Early life health interventions and academic achievement. American Economic Review, 103 (5), 1862-91.

Bingley, P., Jensen, V. M. and Nielsen, S. S. (2015). Maternal employment, childcare, and long-run child outcomes, SFI, The Danish National Centre for Social Research, unpublished manuscript. 
Bitler, M. P., Hoynes, H. W. and Domina, T. (2014). Experimental evidence on distributional effects of Head Start. Working Paper 20434, National Bureau of Economic Research.

Black, S. E., Butikofer, A., Devereux, P. J. and Salvanes, K. G. (2013). This Is Only a Test? Long-Run Impacts of Prenatal Exposure to Radioactive Downfall. Working Paper 18987, National Bureau of Economic Research.

-, Devereux, P. J. and Salvanes, K. G. (2009). Like father, like son? a note on the intergenerational transmission of iq scores. Economics Letters, 105 (1), 138-140.

Bütikofer, A., Løken, K. V. and Salvanes, K. (2014). Long-term consequences of access to well-child visits, Norwegian School of Economics, unpublished manuscript.

Buus, H. (2001). Sundhedsplejerskeinstitutionens Dannelse [The Introduction of the Danish Home Visiting Program]. Museum Tusculanum Press.

Campbell, F., Conti, G., Heckman, J. J., Moon, S. H., Pinto, R., Pungello, E. and PAN, Y. (2014). Early childhood investments substantially boost adult health. Science, 343 (6178), 1478-1485.

Carneiro, P. and Ginja, R. (2012). Long Term Impacts of Compensatory Preschool on Health and Behavior: Evidence from Head Start. IZA Discussion Papers 6315, Institute for the Study of Labor (IZA).

-, Loken, K. V. and Salvanes, K. G. (2011). A flying start? Maternity leave benefits and long run outcomes of children. Discussion Paper 5793, IZA.

Cascio, E. U. (2009). Do investments in universal early education pay off? long-term effects of introducing kindergartens into public schools. Working Paper 14951, National Bureau of Economic Research.

- and Schanzenbach, D. W. (2013). The impacts of expanding access to high-quality preschool education. Working Paper 19735, National Bureau of Economic Research.

Chen, A., Oster, E. and Williams, H. (2014). Why is infant mortality in the us higher than in europe?, University of Chicago, unpublished manuscript.

Chetty, R., Hendren, N., Kline, P., Saez, E. and Turner, N. (2014). Is the united states still a land of opportunity? recent trends in intergenerational mobility. The American Economic Review, 104 (5), 141-147.

Cunha, F. and Heckman, J. (2007). The technology of skill formation. The American Economic Review, 97 (2), 31-47.

-, Heckman, J. J. and Schennach, S. M. (2010). Estimating the technology of cognitive and noncognitive skill formation. Econometrica, 78 (3), 883-931.

Currie, J. (2011). Inequality at birth: Some causes and consequences. The American Economic Review, 101 (3), 1-22.

- and Rossin-Slater, M. (2015). Early-life origins of life-cycle well-being: Research and policy implications. Journal of Policy Analysis and Management, 34 (1), 208-242.

- and Thomas, D. (1995). Does head start make a difference? American Economic Review, 85 (3), 341-364. 
DAhl, G. B. and Lochner, L. (2012). The impact of family income on child achievement: Evidence from the earned income tax credit. The American Economic Review, 102 (5), 1927-1956.

Danish Data Archive (). Statistical Danish Commune Archive. Archive data material.

Datta Gupta, N. and Simonsen, M. (2010). Non-cognitive child outcomes and universal high quality child care. Journal of Public Economics, 94 (1), 30-43.

- and - (2016). Academic performance and type of early childhood care. Economics of Education Review, 53, 217 - 229.

DEming, D. (2009). Early childhood intervention and life-cycle skill development: Evidence from head start. American Economic Journal: Applied Economics, pp. 111-134.

DNBH (1933-1950). Causes of Death in the Kingdom of Denmark. The Danish National Board of Health.

- (1970). Betcnkning Nr 573: Sundhedsplejerske Institutionen [Report on the Danish Home Visiting Program]. The Danish National Board of Health.

- (various years). Medical Report for the Kingdom of Denmark. The Danish National Board of Health.

DST (2008). 60 år $i$ tal - Danmark siden 2. verdenskrig [60 years in numbers - Denmark since WWII]. Statistics Denmark.

FitzPAtrick, M. D. (2008). Starting school at four: The effect of universal pre-kindergarten on children's academic achievement. The BE Journal of Economic Analysis 85 Policy, 8 (1).

Forsdahl, A. (1979). Are poor living conditions in childhood and adolescence an important risk factor for arteriosclerotic heart disease? British Journal of Preventive and Social Medicine, 31 (2), 91-95.

Garces, E., Thomas, D. and Currie, J. (2002). Longer-term effects of head start. The American Economic Review, 92 (4), 999-1012.

Gormley, W. T. and Gayer, T. (2005). Promoting school readiness in oklahoma an evaluation of tulsa's pre-k program. Journal of Human resources, 40 (3), 533-558.

Gunnsteinsson, S., Adhvaryu, A., Christian, P., Labrique, A., Sugimoto, J., Shamim, A. A. and West, K. P. J. (2014). Resilience to early-life shocks, University of Michigan, unpublished manuscript.

Harding, K., Galano, J., Martin, J., Huntington, L. and Schellenbach, C. J.

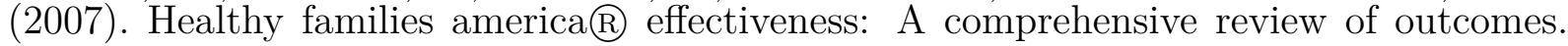
Journal of Prevention \&5 Intervention in the Community, 34 (1-2), 149-179.

Havnes, T. and Mogstad, M. (2011). No child left behind: Subsidized child care and children's long-run outcomes. American Economic Journal: Economic Policy, 3 (2), 97129.

- and - (2015). Is universal child care leveling the playing field? Journal of Public Economics, 127, 100-114.

Heckman, J. and Masterov, D. (2007). The productivity argument for investing in young children. Applied Economic Perspectives and Policy, 29. 
-, Pinto, R. and Savelyev, P. (2013). Understanding the mechanisms through which an influential early childhood program boosted adult outcomes. The American Economic Review, 103 (6), 1-35.

Heckman, J. J., Moon, S. H., Pinto, R., Savelyev, P. A. and Yavitz, A. (2010). The rate of return to the highscope perry preschool program. Journal of Public Economics, 94 (1), 114-128.

Herbst, C. M. and Tekin, E. (2010). Child care subsidies and child development. Economics of Education Review, 29 (4), 618-638.

Huort, J., Sø LVsten, M. and Wüst, M. (2014). Universal investments in infant and long-run health - Evidence from Denmark's 1937 home visiting program. SFI Working Paper 08:2014.

Hoynes, H., Schanzenbach, D. W. and Almond, D. (2016). Long-run impacts of childhood access to the safety net. The American Economic Review, 106 (4), 903-934.

LeE, C.-I. and Solon, G. (2009). Trends in intergenerational income mobility. The Review of Economics and Statistics, 91 (4), 766-772.

Loeb, S., Bridges, M., Bassok, D., Fuller, B. and Rumberger, R. W. (2007). How much is too much? the influence of preschool centers on children's social and cognitive development. Economics of Education Review, 26 (1), 52-66.

Løken, K. V., Mogstad, M. and Wiswall, M. (2012). What linear estimators miss: The effects of family income on child outcomes. American Economic Journal: Applied Economics, 4 (2), 1-35.

Ludwig, J. and Miller, D. (2007). Does head start improve children's life chances? evidence from a regression discontinuity design*. The Quarterly Journal of economics, 122 (1), 159-208.

Magnuson, K. A., Ruhm, C. and Waldfogel, J. (2007). Does prekindergarten improve school preparation and performance? Economics of Education Review, 26 (1), 33-51.

Malamud, O., Pop-Eleches, C. and Urquiola, M. (2015). Understanding interactions between family and school environments in human capital formation, Columbia University, unpublished manuscript.

Masse, L. N. and BARnett, W. S. (2002). A benefit-cost analysis of the abecedarian early childhood intervention. Cost-Effectiveness and Educational Policy, Larchmont, NY: Eye on Education, Inc, pp. 157-173.

Meyer, B. D. and Wherry, L. R. (2012). Saving teens: Using a policy discontinuity to estimate the effects of medicaid eligibility. Working Paper 18309, National Bureau of Economic Research.

Office of Planning, Research, and Evaluation (2010). Head Start Impact Study Final Report. Report.

Olds, D. (2016). Building evidence to improve maternal and child health. The Lancet, 387 (10014), 105-107.

OLDS, D. L. (2006). The nurse-family partnership: An evidence-based preventive intervention. Infant Mental Health Journal, 27 (1), 5-25. 
Olivetti, C. (2013). The female labor force and long-run development: the American experience in comparative perspective. Working Paper 19131, National Bureau of Economic Research.

Pedersen, C. B., Gotzsche, H., Mø ller, J. O. and Mortensen, P. B. (2006). The danish civil registration system. Danish Medical Bulletin, 53 (4), 441-450.

Pedersen, J. (2009). Danmarks økonomiske historie 1910-1960 [Denmark's economic history 1910-1960].

Pedersen, J. H., Petersen, K. and Christiansen, N. F. (eds.) (2011). Dansk velfardshistorie Bind II (1898-1933) [The history of the Danish welfare state, Book II (18981933)].

Poulsen, H. (2002). Besattelsesårene 1940-1945 [The years of occupation 1940-1945].

Robling, M., Bekkers, M.-J., Bell, K., Butler, C. C., Cannings-John, R., Channon, S., Martin, B. C., Gregory, J. W., Hood, K., Kemp, A. et al. (2016). Effectiveness of a nurse-led intensive home-visitation programme for first-time teenage mothers (building blocks): a pragmatic randomised controlled trial. The Lancet, 387 (10014), 146155.

Schweinhart, L. J., Montie, J., Xiang, Z., Barnett, W. S., Belfield, C. R. and Nores, M. (2005). Lifetime effects: The High/Scope Perry Preschool study through age 40. Ypsilanti, MI: High/Scope Press.

Sievertsen, H. H. and Wüst, M. (2015). Discharge on the day of birth, parental response, and health and schooling outcomes, SFI, The Danish National Centre for Social Research, unpublished manuscript.

SKJERnBæK, O. J. (various years). Institutioner til varn for børn og unge $i$ Danmark [Institutions for the protection of children and youth in Denmark].

Solon, G. (1992). Intergenerational income mobility in the united states. The American Economic Review, pp. 393-408.

St. Pierre, R. G. and Layzer, J. I. (1999). Using home visits for multiple purposes: the comprehensive child development program. Future of Children, 9, 134-151.

Wüst, M. (2012). Early interventions and infant health: Evidence from the danish home visiting program. Labour Economics, 19, 484-495. 
Figure 1: Map of Danish Municipalities with an Approved Preschool by 1960

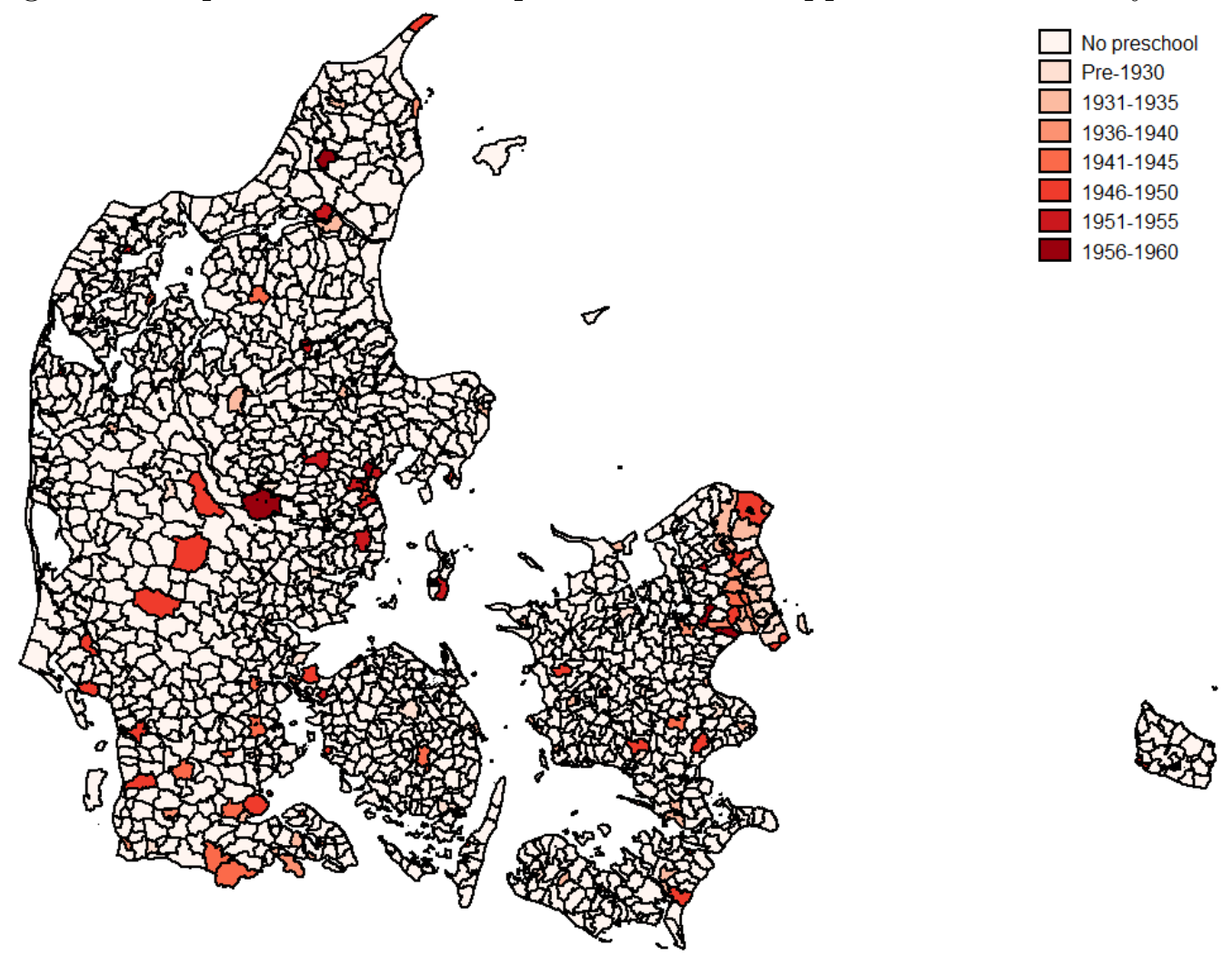

Notes: This map shows the evolution of preschool approvals across Danish municipalities through 1960. Our analysis sample is limited to the 140 municipalities that ever had an approved preschool by 1960 . 
Figure 2: Percent of Municipalities with an Approved Preschool by Year

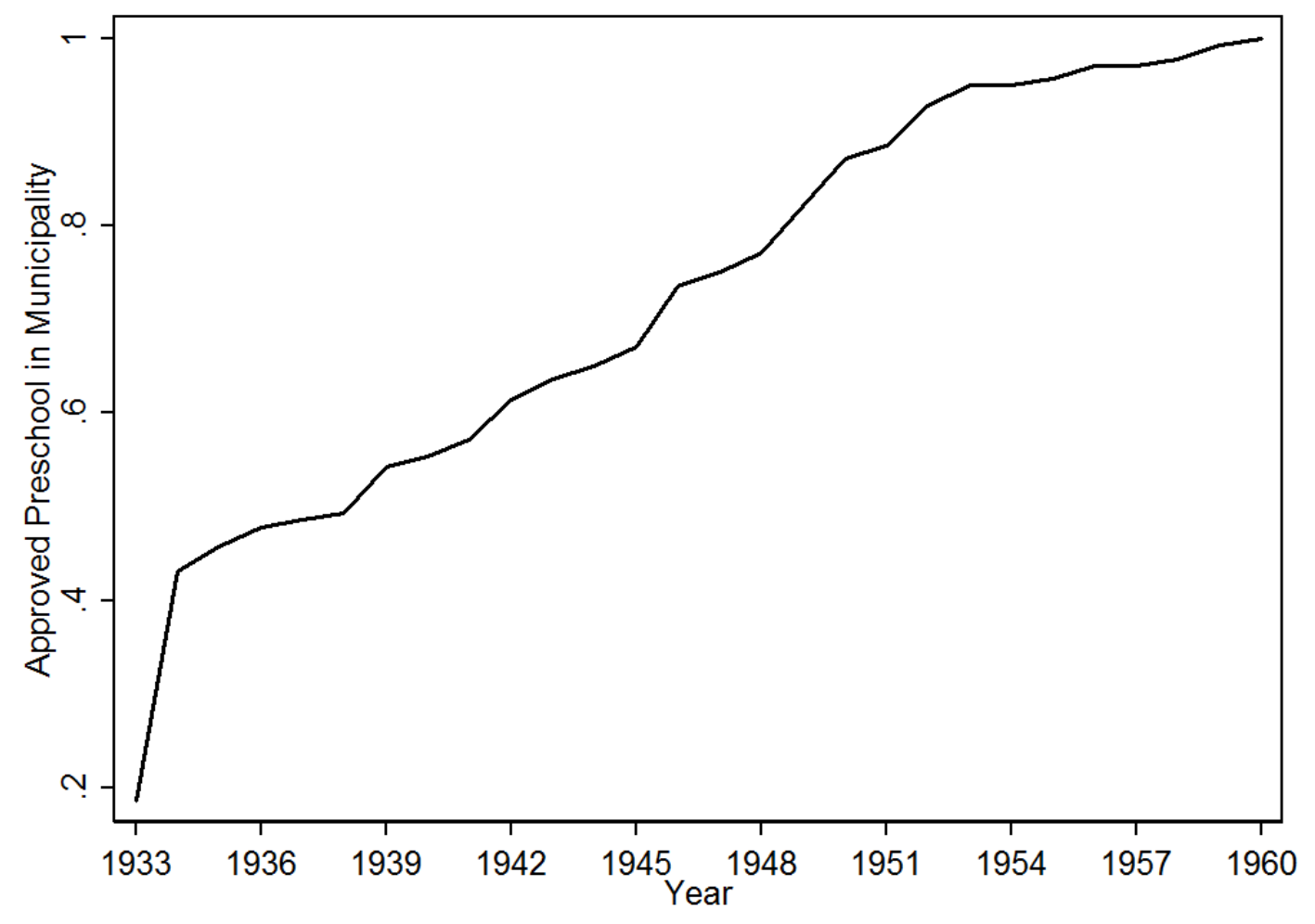

Notes: The sample is limited to the 140 municipalities that ever had an approved preschool by 1960 . This graph shows the percent of municipalities that had an approved preschool in each year. 
Figure 3: Effect of Access to Preschool on Years of Education at Age 50 by Age of Exposure

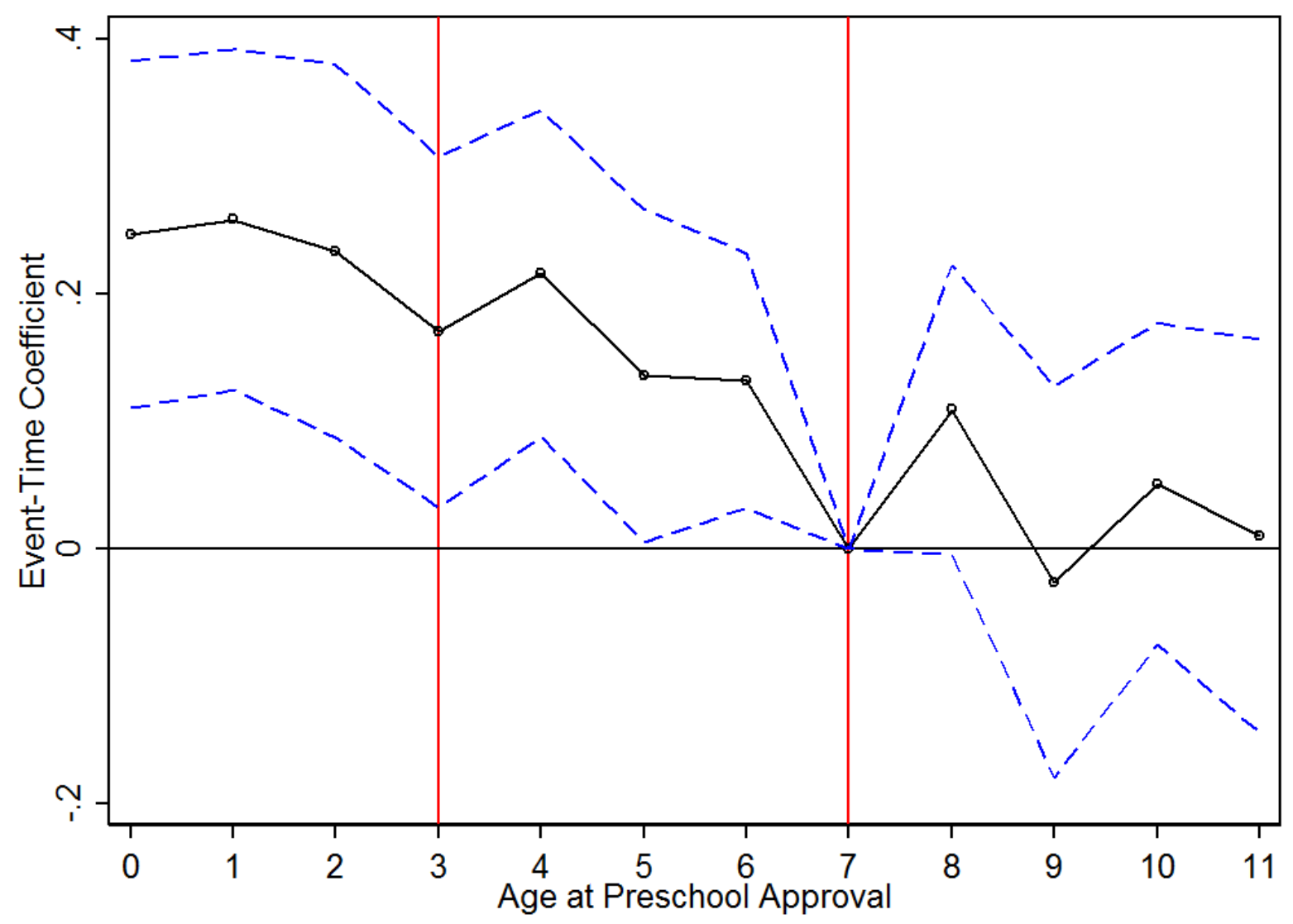

Notes: This figure shows the coefficients and 95\% confidence intervals from an event-study regression estimated on the municipality $\times$ birth-year collapsed data. The sample is limited to the 140 municipalities that ever had an approved preschool by 1960. The regression includes indicators for the cohorts' single years of age in the year of the preschool approval in their municipality of birth between 0 and 11 (with age 7 as the omitted category). The regression also includes an indicator for cohorts being born after the preschool approval (i.e., age less than 0) and an indicator for cohorts being older than age 11 at the time of approval. The regression includes municipality and year-of-birth fixed effects as well as county-specific linear time trends. The regression is weighted by the number of observations in each municipality $\times$ birth-year cell. Standard errors are clustered on the municipality level. 
Figure 4: Effect of Access to Preschool on Indicator for Basic Education at Age 50 by Age of Exposure

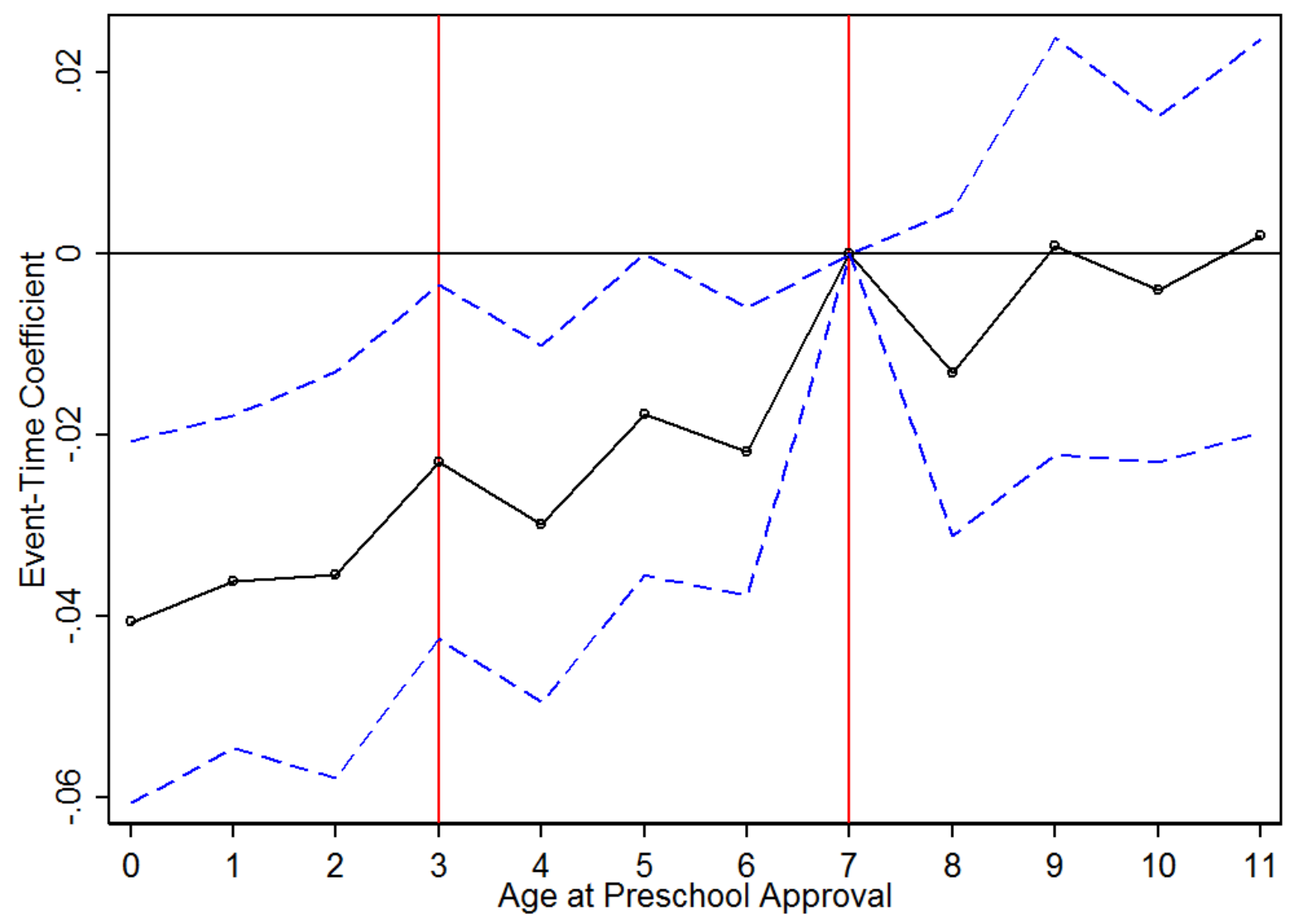

Notes: This figure shows the coefficients and $95 \%$ confidence intervals from an event-study regression estimated on the municipality $\times$ birth-year collapsed data. The sample is limited to the 140 municipalities that ever had an approved preschool by 1960. The regression includes indicators for the cohorts' single years of age in the year of the preschool approval in their municipality of birth between 0 and 11 (with age 7 as the omitted category). The regression also includes an indicator for cohorts being born after the preschool approval (i.e., age less than 0) and an indicator for cohorts being older than age 11 at the time of approval. The regression includes municipality and year-of-birth fixed effects as well as county-specific linear time trends. The regression is weighted by the number of observations in each municipality $\times$ birth-year cell. Standard errors are clustered on the municipality level. 
Figure 5: Effect of Access to Preschool on Log Mean Total Income between Ages 49 and 51 by Age of Exposure for Males

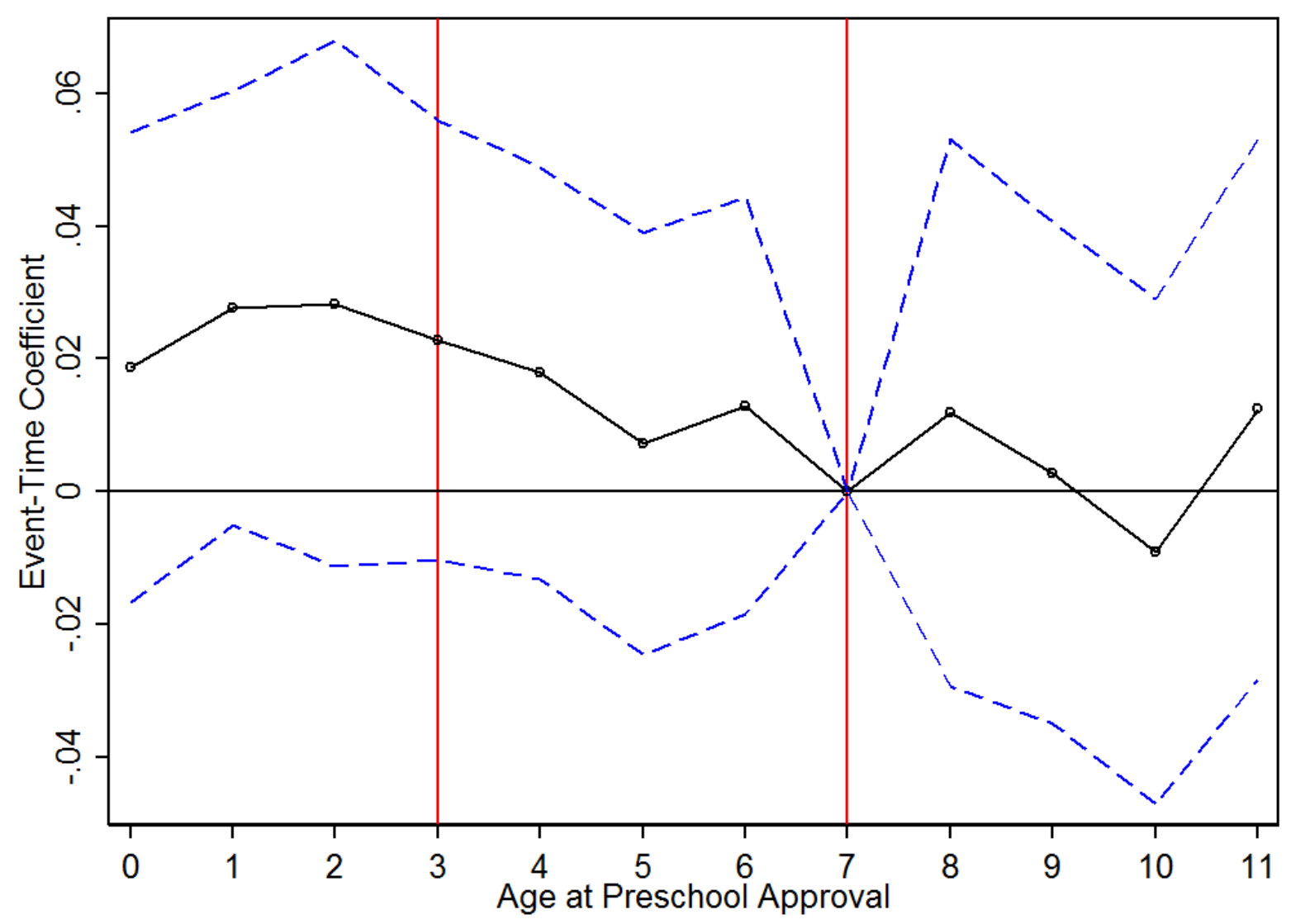

Notes: This figure shows the coefficients and $95 \%$ confidence intervals from an event-study regression estimated on the municipality $\times$ birth-year collapsed data. The sample is limited to the 140 municipalities that ever had an approved preschool by 1960. The regression includes indicators for the cohorts' single years of age in the year of the preschool approval in their municipality of birth between 0 and 11 (with age 7 as the omitted category). The regression also includes an indicator for cohorts being born after the preschool approval (i.e., age less than 0) and an indicator for cohorts being older than age 11 at the time of approval. The regression includes municipality and year-of-birth fixed effects as well as county-specific linear time trends. The regression is weighted by the number of observations in each municipality $\times$ birth-year cell. Standard errors are clustered on the municipality level. 
Figure 6: Effect of Access to Preschool on Survival beyond Age 65 by Age of Exposure for Females

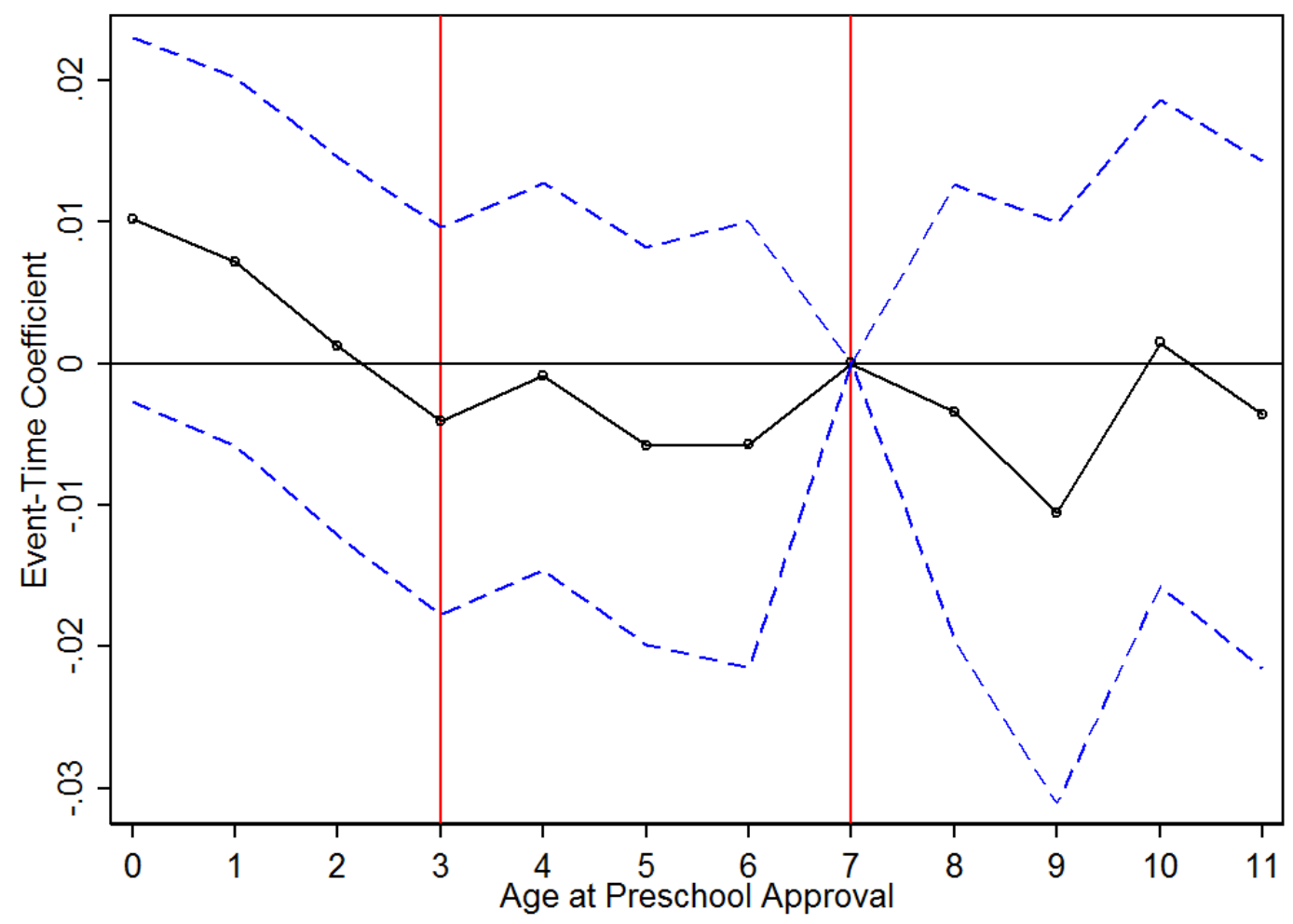

Notes: This figure shows the coefficients and $95 \%$ confidence intervals from an event-study regression estimated on the municipality $\times$ birth-year collapsed data. The sample is limited to the 140 municipalities that ever had an approved preschool by 1960. The regression includes indicators for the cohorts' single years of age in the year of the preschool approval in their municipality of birth between 0 and 11 (with age 7 as the omitted category). The regression also includes an indicator for cohorts being born after the preschool approval (i.e., age less than 0) and an indicator for cohorts being older than age 11 at the time of approval. The regression includes municipality and year-of-birth fixed effects as well as county-specific linear time trends. The regression is weighted by the number of observations in each municipality $\times$ birth-year cell. Standard errors are clustered on the municipality level. 
Table 1: Municipality Characteristics in 1929-1930

(1)

(3)

All Munis Ever Approved Preschool No Approved Preschool

\begin{tabular}{lccc}
\hline Avg. Population & 2650.0 & 13629.5 & 1383.9 \\
Pct Female & 48.76 & 51.47 & 48.43 \\
Pct Social Demo & 25.55 & 46.72 & 23.05 \\
Pct Radical Lib & 14.47 & 8.453 & 15.18 \\
Pct Agrarian Lib & 47.29 & 21.09 & 50.39 \\
Pct Conservatives & 9.761 & 18.90 & 8.680 \\
Pct Industrial & 17.39 & 35.27 & 15.28 \\
Pct Urban & 19.99 & 80.90 & 12.78 \\
Pct Agricultural & 57.08 & 17.62 & 61.75 \\
Rural & & & 0.986 \\
Pct Paying Income & 23.72 & 0.521 & 23.16 \\
Tax & & & 6.385 \\
Log Taxable Income & 6.585 & 28.48 & \\
Pct Paying Property & 5.806 & 8.276 & \\
\hline Num. Munis & 1,354 & & \\
\hline Nax & & & \\
\hline
\end{tabular}

Notes: Column (1) reports the means of municipality characteristics for all Danish municipalities with available data. Column (2) limits the sample to the 140 municipalities that ever had an approved preschool by 1960. Column (3) limits the sample to the other municipalities that never had an approved preschool by 1960. 


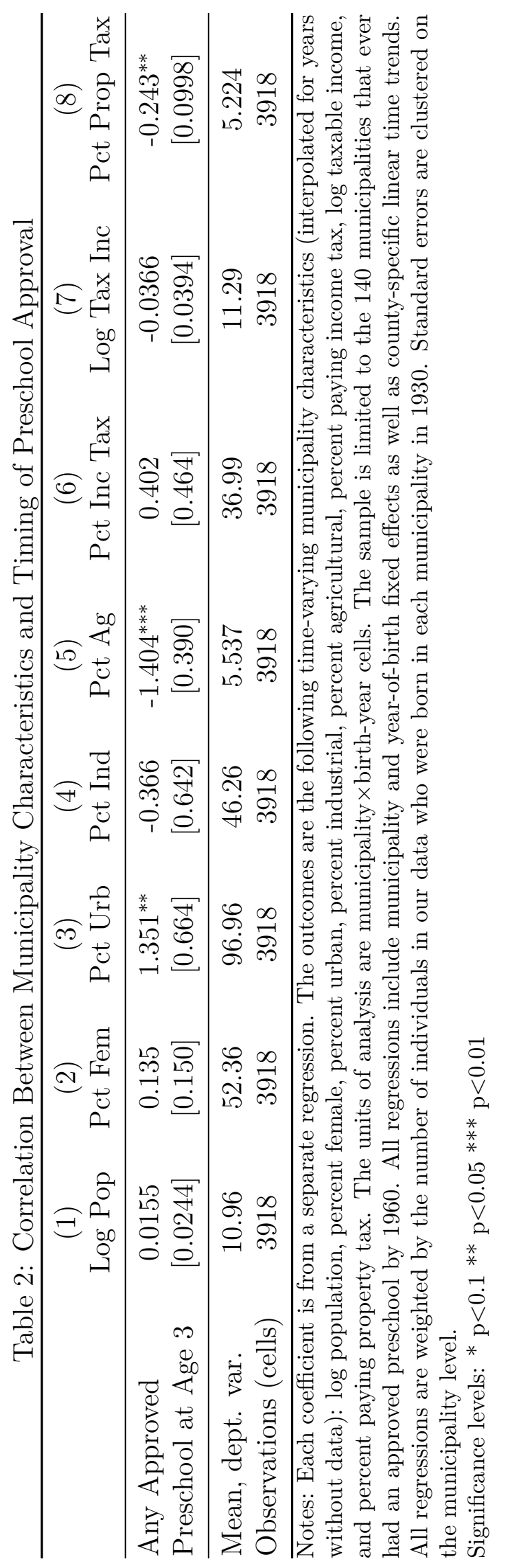


Table 3: Correlation between Access to the NHV at Birth and Access to Preschool at Age 3

(1)

NHV at Birth
$(2)$

Any Approved Preschool at Age 3

\begin{tabular}{ll}
\hline Any Approved & 0.00862 \\
Preschool at Age 3 & {$[0.0433]$}
\end{tabular}

NHV at Birth

0.00578

$[0.0292]$

\begin{tabular}{lcc}
\hline Mean, dept. var. & 0.733 & 0.909 \\
Observations (cells) & 3918 & 3918
\end{tabular}

Notes: Each column reports the results from a separate regression. The units of analysis are municipality $\times$ birth-year cells. The sample is limited to the 140 municipalities that ever had an approved preschool by 1960. All regressions include municipality and year-of-birth fixed effects as well as county-specific linear time trends. All regressions are weighted by the number of observations in each municipality $\times$ birthyear cell. Standard errors are clustered on the municipality level.

Significance levels: $* \mathrm{p}<0.1 * * \mathrm{p}<0.05 * * * \mathrm{p}<0.01$ 
Table 4: Effect of Access to Preschool at Age 3 on Education, Income, and Survival

\begin{tabular}{|c|c|c|c|c|}
\hline Outcome & $\begin{array}{l}(1) \\
\text { (All) }\end{array}$ & $\begin{array}{l}(2) \\
(\text { All })\end{array}$ & $\begin{array}{l}(3) \\
\text { (All) }\end{array}$ & $\begin{array}{l}(4) \\
\text { (All) }\end{array}$ \\
\hline Yrs. School & $\begin{array}{c}0.284^{* * *} \\
(0.088)\end{array}$ & $\begin{array}{c}0.189^{* * *} \\
(0.046)\end{array}$ & $\begin{array}{l}0.074^{* *} \\
(0.034)\end{array}$ & $\begin{array}{c}0.206^{* *} \\
(0.087)\end{array}$ \\
\hline Mean of dep. var. & 12.075 & 12.075 & 12.075 & 12.075 \\
\hline No. of obs. & 3918 & 3918 & 3918 & 3918 \\
\hline Basic Educ. & $\begin{array}{c}-0.038^{* * *} \\
(0.011)\end{array}$ & $\begin{array}{c}-0.029^{* * *} \\
(0.006)\end{array}$ & $\begin{array}{c}-0.013^{* * *} \\
(0.005)\end{array}$ & $\begin{array}{c}-0.037^{* * *} \\
(0.012)\end{array}$ \\
\hline Mean of dep. var. & 0.299 & 0.299 & 0.299 & 0.299 \\
\hline No. of obs. & 3918 & 3918 & 3918 & 3918 \\
\hline Log Tot Inc. & $\begin{array}{c}0.040^{* * *} \\
(0.014)\end{array}$ & $\begin{array}{c}0.015^{* *} \\
(0.007)\end{array}$ & $\begin{array}{c}0.009 \\
(0.008)\end{array}$ & $\begin{array}{l}0.024^{*} \\
(0.013)\end{array}$ \\
\hline $\begin{array}{l}\text { Mean of dep. var. } \\
\text { No. of obs. }\end{array}$ & $\begin{array}{c}12.557 \\
3778\end{array}$ & $\begin{array}{c}12.557 \\
3778\end{array}$ & $\begin{array}{c}12.557 \\
3778\end{array}$ & $\begin{array}{c}12.557 \\
3778\end{array}$ \\
\hline Survival beyond age 65 & $\begin{array}{l}0.005^{* *} \\
(0.002)\end{array}$ & $\begin{array}{c}0.005^{* *} \\
(0.002)\end{array}$ & $\begin{array}{c}0.005^{* *} \\
(0.002)\end{array}$ & $\begin{array}{c}0.004 \\
(0.004)\end{array}$ \\
\hline $\begin{array}{l}\text { Mean of dep. var. } \\
\text { No. of obs. }\end{array}$ & $\begin{array}{l}0.903 \\
3918\end{array}$ & $\begin{array}{c}0.903 \\
3918\end{array}$ & $\begin{array}{l}0.903 \\
3918\end{array}$ & $\begin{array}{c}0.903 \\
3918\end{array}$ \\
\hline $\begin{array}{l}\text { Cohort FE } \\
\text { Muncipality: }\end{array}$ & Yes & Yes & Yes & Yes \\
\hline $\mathrm{FE}$ & Yes & Yes & Yes & Yes \\
\hline X (ipolated) & No & No & Yes & No \\
\hline $\mathrm{FE} \times$ pre-trend & No & No & No & Yes \\
\hline Linear county time trends & No & Yes & Yes & No \\
\hline
\end{tabular}

Notes: Each cell presents the coefficient for the treatment indicator for a separate regression. The units of analysis are municipality $\times$ birth-year cells. The sample is limited to the 140 municipalities that ever had an approved preschool by 1960 . When studying survival beyond age 65 , the sample is limited to only those individuals who have survived to at least age 50 . All regressions are weighted by the number of observations in each municipality $\times$ birth-year cell. Standard errors are clustered on the municipality level.

Significance levels: ${ }^{*} \mathrm{p}<0.1{ }^{* *} \mathrm{p}<0.05 * * * \mathrm{p}<0.01$ 
Table 5: Effect of Access to Preschool at Age 3 on Adult Labor Market Outcomes

\begin{tabular}{lcccc}
\hline Outcome & $(1)$ & $(2)$ & $(3)$ & $(4)$ \\
& $($ All $)$ & $($ All $)$ & $($ All $)$ & $($ All $)$ \\
\hline Log Wage Inc. & $0.033^{* * *}$ & $0.015^{*}$ & 0.008 & 0.014 \\
& $(0.012)$ & $(0.008)$ & $(0.008)$ & $(0.017)$ \\
Mean of dep. var. & 12.429 & 12.429 & 12.429 & 12.429 \\
No. of obs. & 3777 & 3777 & 3777 & 3777 \\
\hline Any Wage Inc. & $0.009^{* *}$ & 0.004 & 0.003 & 0.005 \\
& $(0.004)$ & $(0.002)$ & $(0.003)$ & $(0.006)$ \\
Mean of dep. var. & 0.898 & 0.898 & 0.898 & 0.898 \\
No. of obs. & 3777 & 3777 & 3777 & 3777 \\
\hline Blue Collar Occ. & -0.006 & -0.004 & -0.006 & -0.021 \\
& $(0.007)$ & $(0.006)$ & $(0.005)$ & $(0.031)$ \\
Mean of dep. var. & 0.336 & 0.336 & 0.336 & 0.336 \\
No. of obs. & 2380 & 2380 & 2380 & 2380 \\
\hline Cohort FE & Yes & Yes & Yes & Yes \\
Muncipality: & & & & \\
FE & Yes & Yes & Yes & Yes \\
X (ipolated) & No & No & Yes & No \\
FE $\times$ pre-trend & No & No & No & Yes \\
Linear county time trends & No & Yes & Yes & No \\
\hline
\end{tabular}

Notes: Each cell presents the coefficient for the treatment indicator for a separate regression. The units of analysis are municipality $\times$ birth-year cells. The sample is limited to the 140 municipalities that ever had an approved preschool by 1960. All regressions are weighted by the number of observations in each municipality $\times$ birth-year cell. Standard errors are clustered on the municipality level.

Significance levels: ${ }^{*} \mathrm{p}<0.1 * * \mathrm{p}<0.05^{* * *} \mathrm{p}<0.01$ 


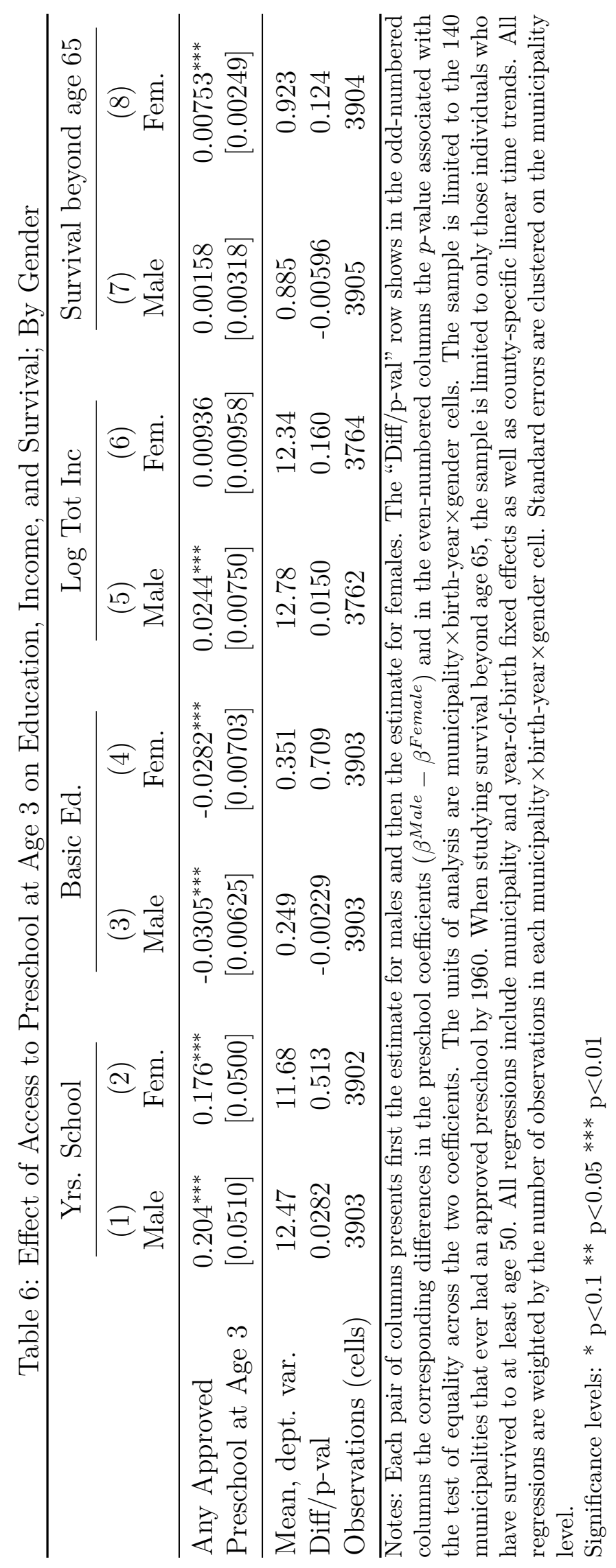


Table 7: Effect of Access to Preschool at Age 3 on Adult Labor Market Outcomes; By Gender

\begin{tabular}{|c|c|c|c|c|c|c|}
\hline & \multicolumn{2}{|c|}{ Log Wage Inc. } & \multicolumn{2}{|c|}{ Any Wage Inc. } & \multicolumn{2}{|c|}{ Blue Collar Occ. } \\
\hline & $(1)$ & $(2)$ & $(3)$ & $(4)$ & $(5)$ & $(6)$ \\
\hline & Male & Fem. & Male & Fem. & Male & Fem. \\
\hline Any Approved & $0.0250^{* *}$ & 0.00589 & $0.00634^{* *}$ & 0.00229 & -0.00969 & 0.00442 \\
\hline Preschool at Age 3 & {$[0.0105]$} & {$[0.0102]$} & {$[0.00309]$} & {$[0.00318]$} & {$[0.00774]$} & {$[0.00659]$} \\
\hline Mean, dept. var. & 12.62 & 12.22 & 0.924 & 0.873 & 0.451 & 0.221 \\
\hline Diff/p-val & 0.0192 & 0.145 & 0.00404 & 0.288 & -0.0141 & 0.105 \\
\hline Observations (cells) & 3760 & 3759 & 3761 & 3763 & 2373 & 2368 \\
\hline
\end{tabular}

Notes: Each pair of columns presents first the estimate for males and then the estimate for females. The "Diff/p-val" row shows in the odd-numbered columns the corresponding differences in the preschool coefficients $\left(\beta^{\text {Male }}-\beta^{\text {Female }}\right)$ and in the even-numbered columns the $p$-value associated with the test of equality across the two coefficients. The units of analysis are municipality $\times$ birth-year $\times$ gender cells. The sample is limited to the 140 municipalities that ever had an approved preschool by 1960. All regressions include municipality and year-of-birth fixed effects as well as county-specific linear time trends. All regressions are weighted by the number of observations in each municipality $\times$ birth-year $\times$ gender cell. Standard errors are clustered on the municipality level.

Significance levels: ${ }^{*} \mathrm{p}<0.1 * * \mathrm{p}<0.05 * * * \mathrm{p}<0.01$ 


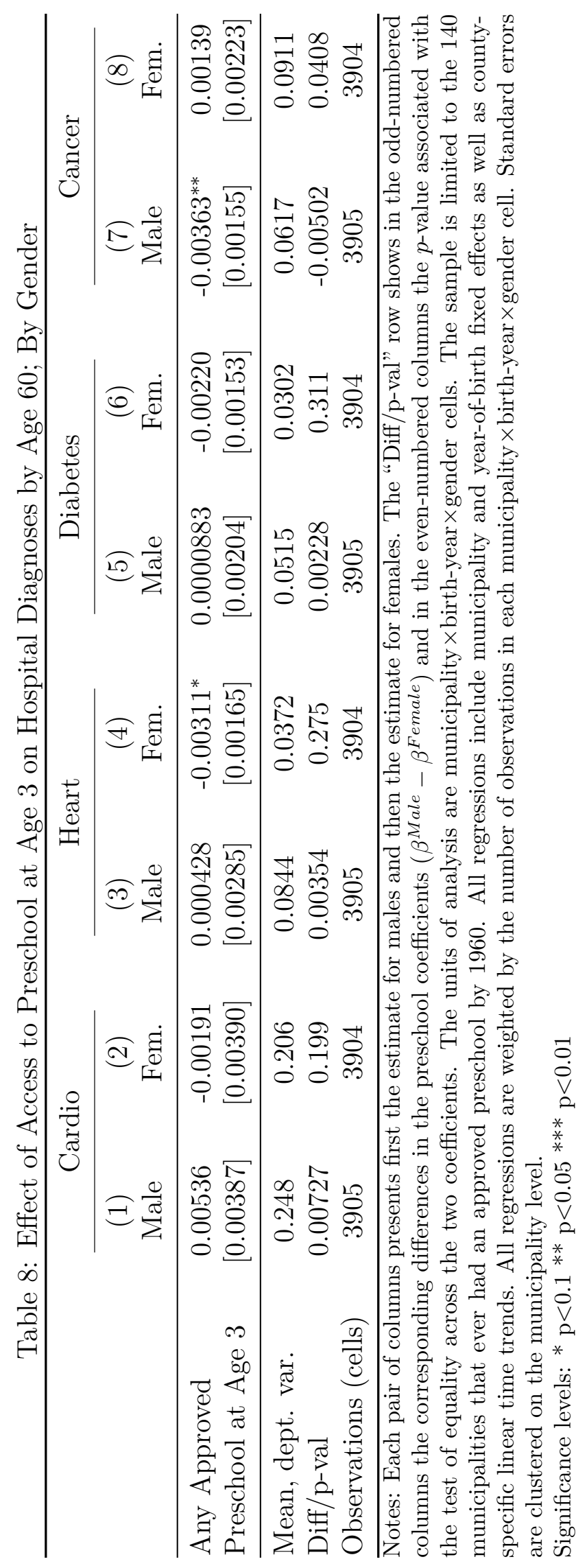


Table 9: Effect of Access to Preschool at Age 3 on the Education of the Next Generation

\begin{tabular}{lcccc}
\hline Outcome & $(1)$ & $(2)$ & $(3)$ & $(4)$ \\
& $($ All $)$ & $($ All $)$ & $($ All $)$ & $($ All $)$ \\
\hline Child's years of schoolong & $0.056^{* *}$ & $0.043^{* *}$ & 0.030 & 0.103 \\
& $(0.025)$ & $(0.021)$ & $(0.022)$ & $(0.080)$ \\
Mean of dep. var. & 12.338 & 12.338 & 12.338 & 12.338 \\
No. of obs. & 3197 & 3197 & 3197 & 3197 \\
\hline Child has basic education & $-0.022^{* * *}$ & $-0.014^{* * *}$ & $-0.011^{* *}$ & $-0.028^{*}$ \\
& $(0.006)$ & $(0.004)$ & $(0.005)$ & $(0.017)$ \\
Mean of dep. var. & 0.225 & 0.225 & 0.225 & 0.225 \\
No. of obs. & 3197 & 3197 & 3197 & 3197 \\
\hline \multirow{2}{*}{ Child has completed gymnasium } & $0.023^{* * *}$ & $0.009^{*}$ & 0.008 & 0.016 \\
& $(0.007)$ & $(0.005)$ & $(0.005)$ & $(0.022)$ \\
Mean of dep. var. & 0.253 & 0.253 & 0.253 & 0.253 \\
No. of obs. & 3197 & 3197 & 3197 & 3197 \\
\hline Cohort FE & Yes & Yes & Yes & Yes \\
Muncipality: & & & & \\
FE & Yes & Yes & Yes & Yes \\
X (ipolated) & No & No & Yes & No \\
FE $\times$ pre-trend & No & No & No & Yes \\
Linear county time trends & No & Yes & Yes & No \\
\hline
\end{tabular}

Notes: Each cell presents the coefficient for the treatment indicator for a separate regression. The units of analysis are municipality $\times$ birth-year cells. The sample is limited to the 140 municipalities that ever had an approved preschool by 1960. All regressions are weighted by the number of observations in each municipality $\times$ birth-year cell. Standard errors are clustered on the municipality level.

Significance levels: $* \mathrm{p}<0.1 * * \mathrm{p}<0.05^{* * *} \mathrm{p}<0.01$ 
Table 10: Interaction Effect between Access to NHV at Birth and Access to Preschool at Age 3 on Education, Income, and Survival

\begin{tabular}{|c|c|c|c|c|}
\hline & \multicolumn{3}{|c|}{ Outcomes at Age 50} & \multirow[b]{2}{*}{$\begin{array}{c}(4) \\
\text { Survival beyond age } 65\end{array}$} \\
\hline & $\begin{array}{c}\text { (1) } \\
\text { Yrs. School }\end{array}$ & $\begin{array}{c}(2) \\
\text { Basic Ed. }\end{array}$ & $\begin{array}{c}(3) \\
\text { Log Tot Inc }\end{array}$ & \\
\hline Any Approved & $0.224^{* * *}$ & $-0.0344^{* * *}$ & $0.0178^{* *}$ & $0.00505^{* *}$ \\
\hline Preschool at Age 3 & {$[0.0490]$} & {$[0.00636]$} & {$[0.00839]$} & {$[0.00237]$} \\
\hline NHV at Birth & $\begin{array}{l}0.193^{* * *} \\
{[0.0504]}\end{array}$ & $\begin{array}{c}-0.0257^{* * *} \\
{[0.00645]}\end{array}$ & $\begin{array}{c}0.0270^{* * *} \\
{[0.0100]}\end{array}$ & $\begin{array}{l}0.00586^{* *} \\
{[0.00256]}\end{array}$ \\
\hline Preschool x NHV & $\begin{array}{c}-0.191^{* * *} \\
{[0.0428]}\end{array}$ & $\begin{array}{l}0.0285^{* * *} \\
{[0.00589]}\end{array}$ & $\begin{array}{l}-0.0159^{*} \\
{[0.00927]}\end{array}$ & $\begin{array}{l}-0.00312 \\
{[0.00251]}\end{array}$ \\
\hline Mean, dept. var. & 12.07 & 0.299 & 12.56 & 0.903 \\
\hline Observations (cells) & 3918 & 3918 & 3778 & 3918 \\
\hline $\begin{array}{l}\text { Notes: Each column } \\
\text { municipality } \times \text { birth-year } \\
\text { preschool by } 1960 \text {. Whe } \\
\text { who have survived to at } \\
\text { well as county-specific lir } \\
\text { municipality } \times \text { birth-year }\end{array}$ & $\begin{array}{l}\text { ts the rest } \\
\text { The samp } \\
\text { dying survis } \\
\text { age } 50 \text {. All } \\
\text { ime trends. } \\
\text { Standard er }\end{array}$ & $\begin{array}{l}\text { yond age } \\
\text { ssions inc } \\
\text { gressions }\end{array}$ & $\begin{array}{l}\text { e regressior } \\
40 \text { municipa } \\
\text { te sample is } \\
\text { municipality } \\
\text { eighted by t] }\end{array}$ & $\begin{array}{l}\text { The units of analysis are } \\
\text { s that ever had an approved } \\
\text { ted to only those individuals } \\
\text { year-of-birth fixed effects as } \\
\text { imber of observations in each } \\
\text { level. }\end{array}$ \\
\hline
\end{tabular}

Significance levels: ${ }^{*} \mathrm{p}<0.1{ }^{* *} \mathrm{p}<0.05 * * * \mathrm{p}<0.01$ 


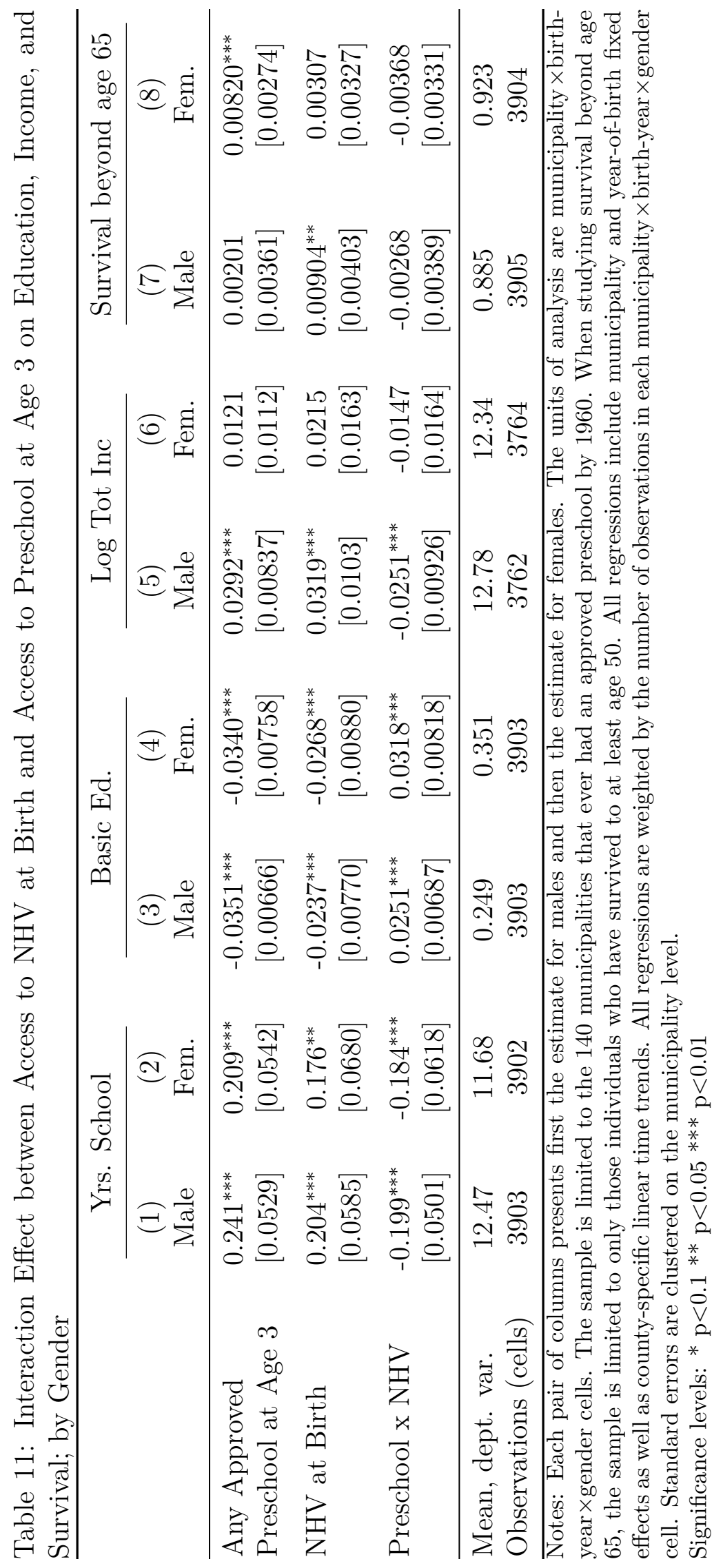




\section{A Additional Results}

Appendix Figure 1: Variation in Preschool and NHV Availability by Year of Birth
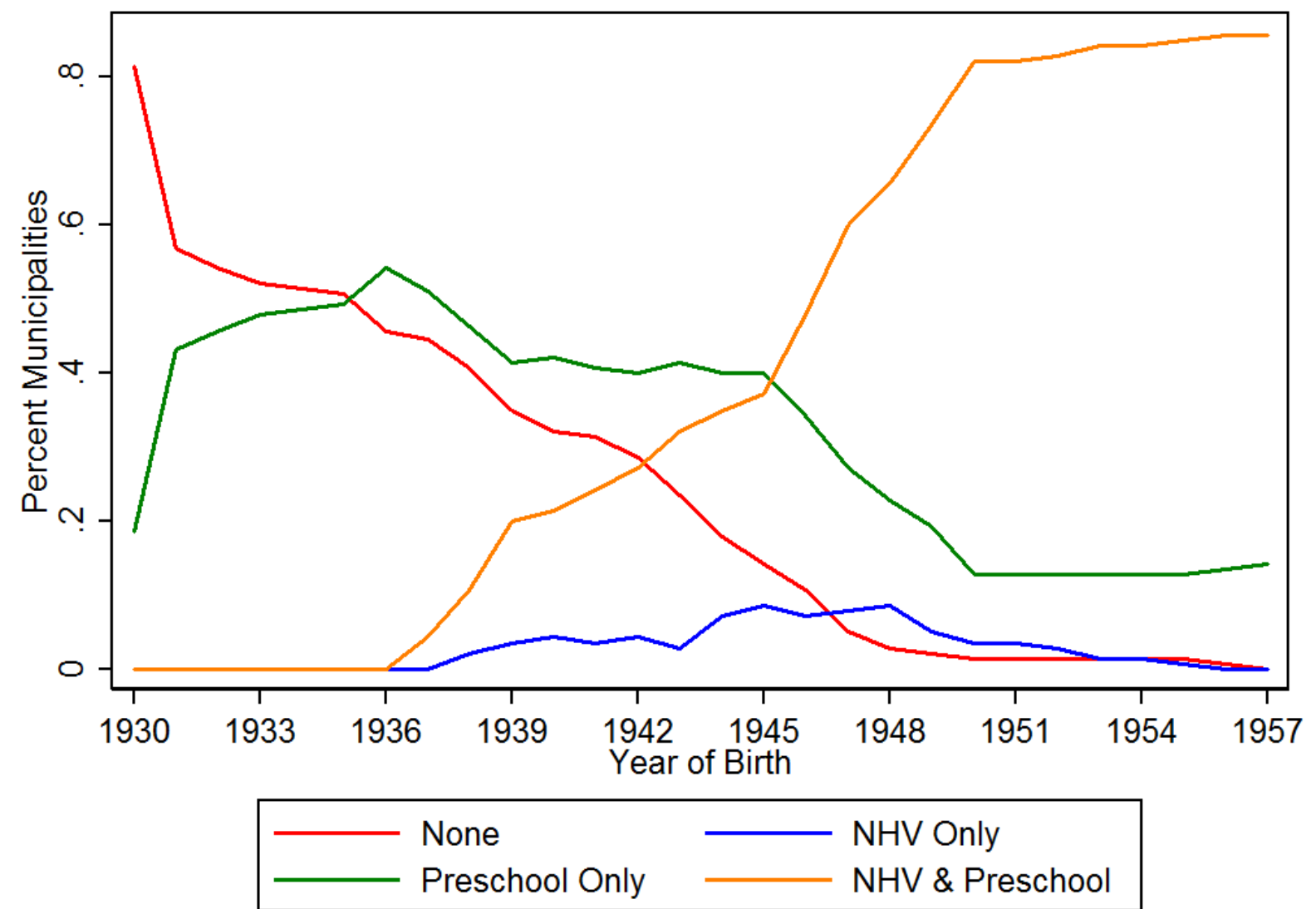

Notes: This graph shows for each cohort the percent of municipalities that had: (1) no preschool at age 3 and no NHV at birth in red; (2) preschool at age 3 but no NHV at birth in green; (3) NHV at birth but no preschool at age 3 in blue; and (4) preschool at age 3 and NHV at birth in orange. The sample is limited to the 140 municipalities that ever had an approved preschool by 1960 . 
Appendix Figure 2: Valid Parish Codes Among Danish-Born Individuals in the Outcome Data

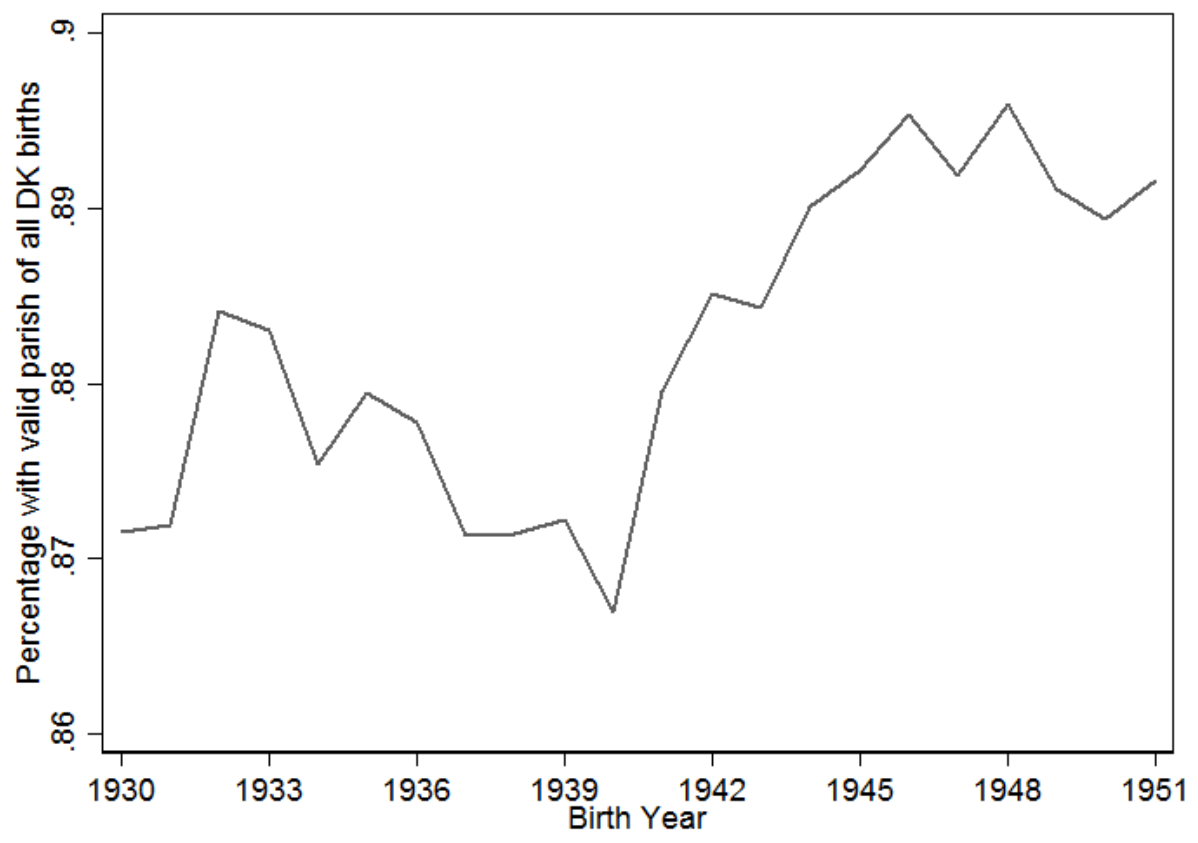

Appendix Figure 3: Comparison of First-Year Survivors to All Danish-Born Individuals in the Outcome Data

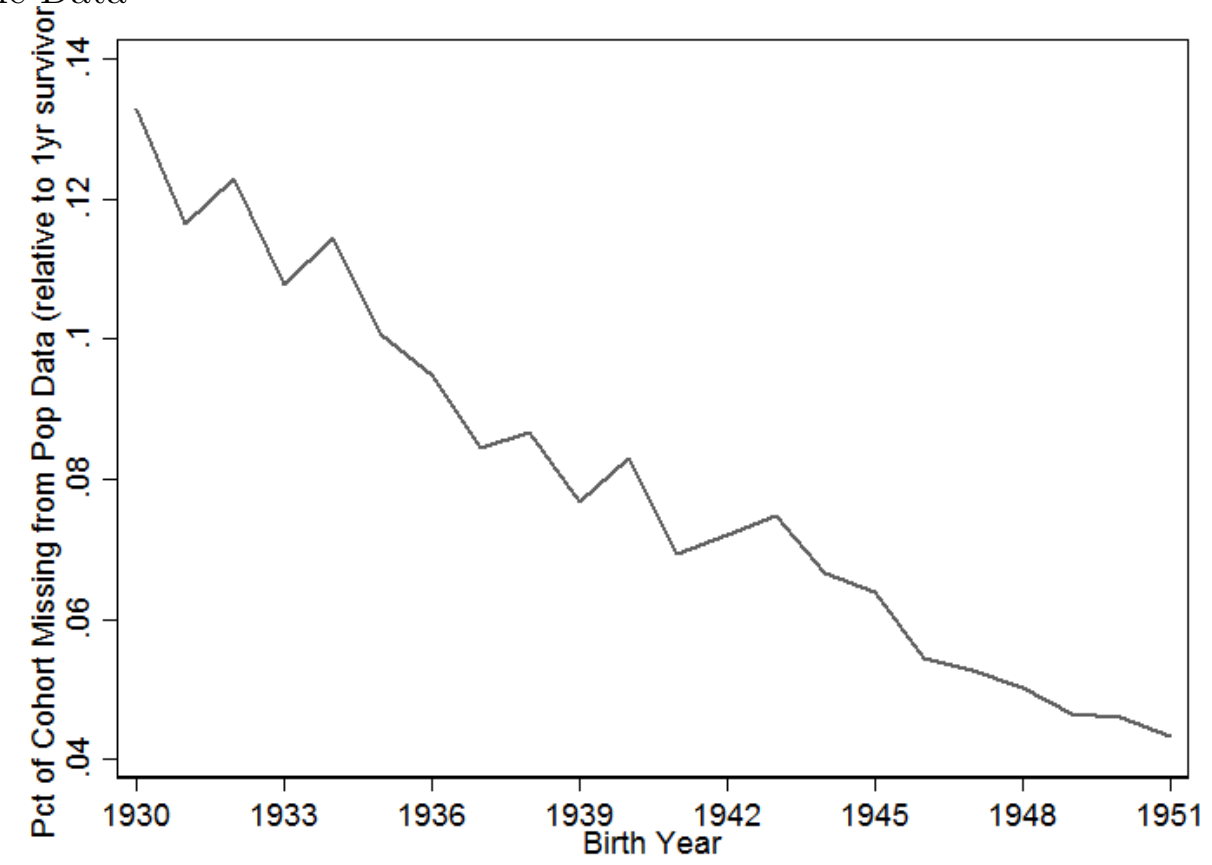


Appendix Figure 4: Effect of Access to Preschool at Age 3 on Survival by Age of Follow-Up for Females

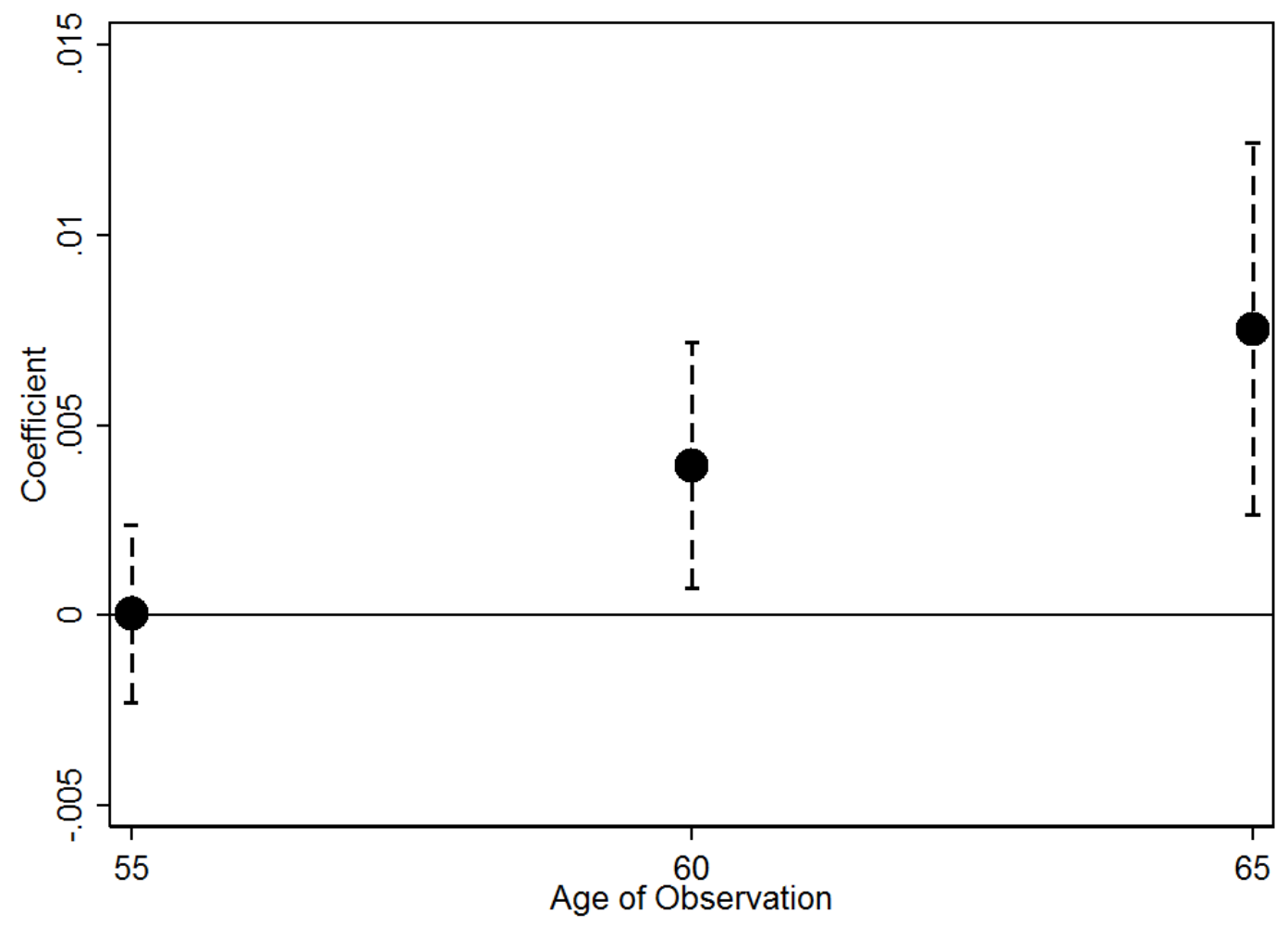

Notes: This figure shows the coefficients and $95 \%$ confidence intervals from separate regressions estimated on the municipality $\times$ birth-year $\times$ gender collapsed data. The sample is limited to females born in the 140 municipalities that ever had an approved preschool by 1960. Additionally, the sample is limited to only those individuals who have survived to at least age 50. The coefficients plotted estimate the effect of access to preschool at age 3 on the outcome listed observed by the age reported on the x-axis. Each regression includes municipality and year-of-birth fixed effects as well as county-specific linear time trends. All regressions are weighted by the number of observations in each municipality $\times$ birth-year cell. Standard errors are clustered on the municipality level. 
Appendix Table 1: Correlation between Share of Cohort "Not Missing" and Access to Preschool; Urban Municipalities.

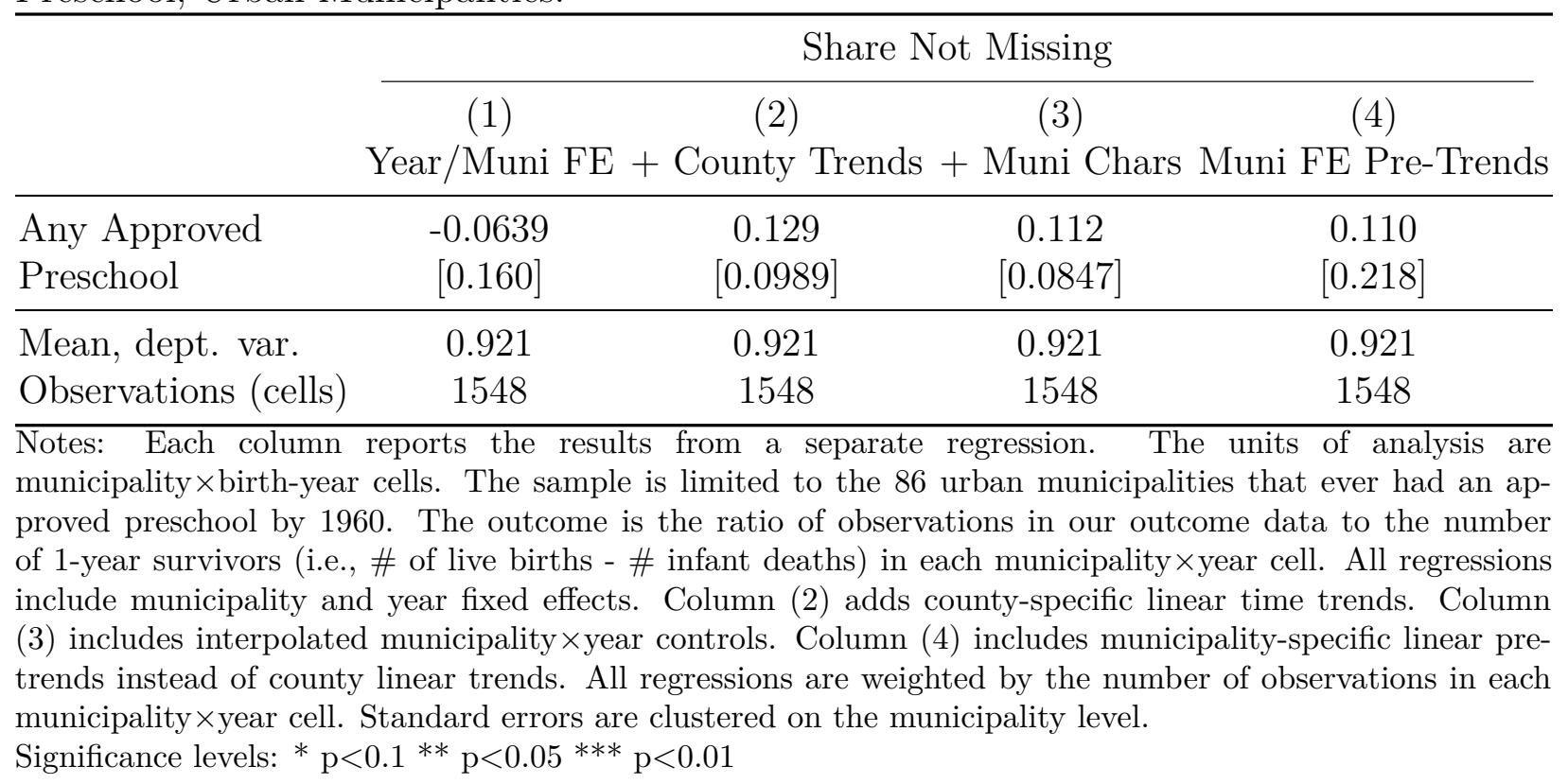




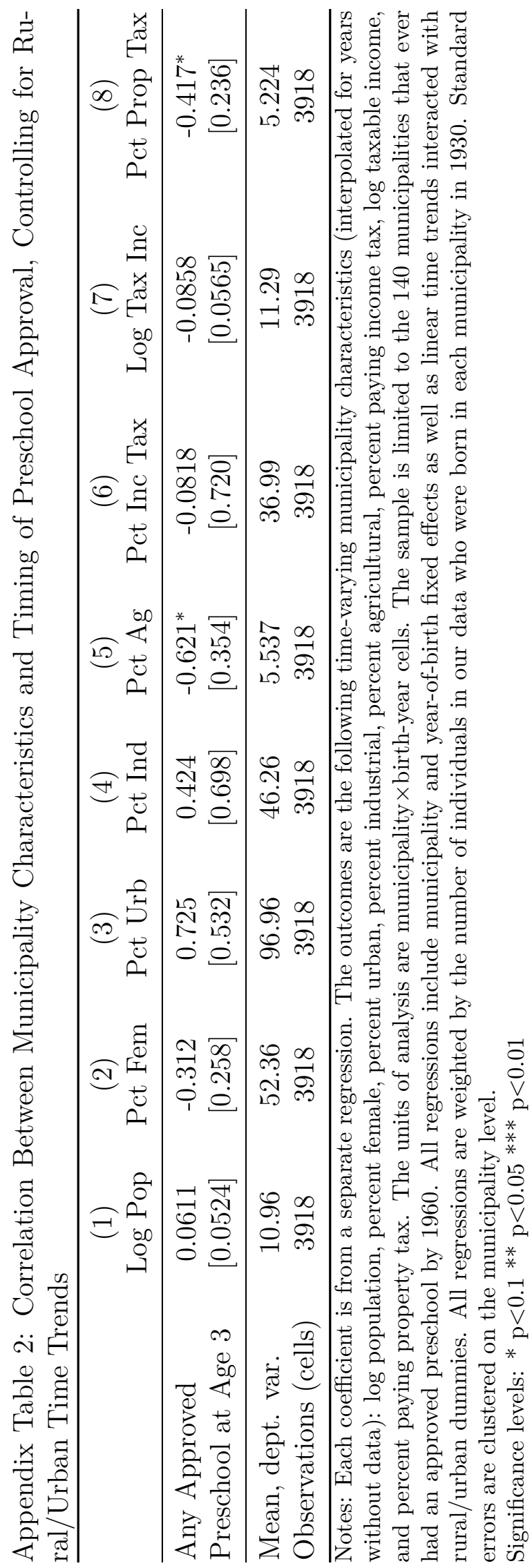




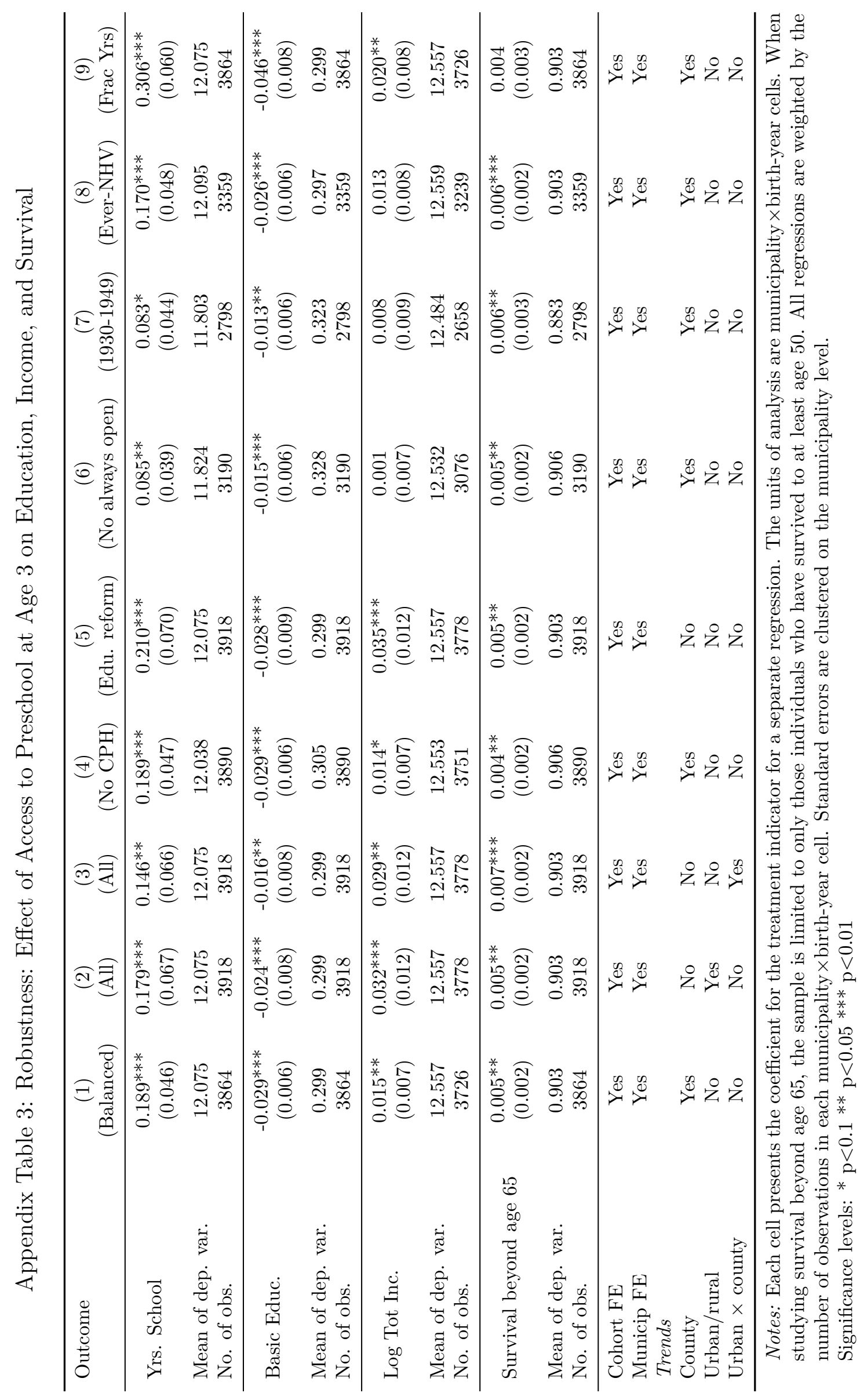


Appendix Table 4: Annual Averages: Number of Preschool Enrollees; Number of Relevant Children Aged 3-7; Share of Children in Preschool. Sample: 86 Urban Municipalities.

\begin{tabular}{cccc}
\hline Year & No. of Children Enrolled & No. of Children Aged 3-7 & Share in Preschool \\
\hline 1940 & 177.71 & 2280.12 & 0.09 \\
1941 & 184.20 & 2409.94 & 0.09 \\
1942 & 182.23 & 2342.54 & 0.12 \\
1943 & 190.25 & 2462.59 & 0.12 \\
1944 & 205.16 & 2556.71 & 0.12 \\
1945 & 215.46 & 2705.71 & 0.12 \\
1946 & 215.47 & 2781.50 & 0.11 \\
1947 & 232.12 & 2998.12 & 0.10 \\
1948 & 246.52 & 3116.83 & 0.09 \\
1949 & 260.07 & 3255.67 & 0.09 \\
1950 & 252.01 & 2991.87 & 0.08 \\
Total & 216.50 & 2737.46 & 0.10 \\
\hline
\end{tabular}

Notes: The sample is limited to urban municipality $\times$ year cells over 1940-1950 with an approved preschool.

Appendix Table 5: Effect of Access to Preschool at Age 3 on the Fertility Outcomes of Females born in 1935-1957

(2)

(3)

(4)

No Kids Num. Kids Age at Fst. Birth Dad Ever Miss.

\begin{tabular}{lcccc}
\hline Any Approved & $-0.00592^{*}$ & 0.000673 & $0.0793^{*}$ & -0.00217 \\
Preschool at Age 3 & {$[0.00340]$} & {$[0.0138]$} & {$[0.0428]$} & {$[0.00335]$} \\
\hline Mean, dept. var. & 0.115 & 1.904 & 24.15 & 0.154 \\
Observations (cells) & 3207 & 3207 & 3202 & 3207 \\
\hline
\end{tabular}

Notes: Each column reports the results from a separate regression. The sample is limited to females who were born in 1935-1957 in the 140 municipalities that ever had an approved preschool by 1960. The units of analysis are municipality $\times$ birth-year cells. All regressions include municipality and year-of-birth fixed effects as well as county-specific linear time trends. All regressions are weighted by the number of observations in each municipality $\times$ birth-year cell. Standard errors are clustered on the municipality level.

Significance levels: ${ }^{*} \mathrm{p}<0.1 * * \mathrm{p}<0.05 * * * \mathrm{p}<0.01$ 
Appendix Table 6: Interaction Effect between Access to NHV at Birth and Access to Preschool at Age 3 on Education, Income, and Survival; No Time Trends

Outcomes at Age 50
(1)
(2)
(3)
(4)

Yrs. School Basic Ed. Log Tot Inc Survival beyond age 65

\begin{tabular}{lcccc}
\hline Any Approved & $0.319^{* * *}$ & $-0.0428^{* * *}$ & $0.0426^{* * *}$ & $0.00532^{* *}$ \\
Preschool at Age 3 & {$[0.0896]$} & {$[0.0109]$} & {$[0.0149]$} & {$[0.00223]$} \\
NHV at Birth & $0.257^{* * *}$ & $-0.0342^{* * *}$ & $0.0412^{* * *}$ & $0.00506^{* *}$ \\
& {$[0.0670]$} & {$[0.00843]$} & {$[0.0134]$} & {$[0.00238]$} \\
Preschool x NHV & $-0.232^{* * *}$ & $0.0336^{* * *}$ & $-0.0251^{* *}$ & -0.00290 \\
& {$[0.0541]$} & {$[0.00721]$} & {$[0.0116]$} & {$[0.00232]$} \\
\hline Mean, dept. var. & 12.07 & 0.299 & 12.56 & 0.903 \\
Observations (cells) & 3918 & 3918 & 3778 & 3918 \\
\hline
\end{tabular}

Notes: Each column reports the results from a separate regression. The units of analysis are municipality $\times$ birth-year cells. The sample is limited to the 140 municipalities that ever had an approved preschool by 1960 . When studying survival beyond age 65 , the sample is limited to only those individuals who have survived to at least age 50. All regressions include municipality and year-of-birth fixed effects. All regressions are weighted by the number of observations in each municipality $\times$ birth-year cell. Standard errors are clustered on the municipality level.

Significance levels: $* \mathrm{p}<0.1 * * \mathrm{p}<0.05 * * * \mathrm{p}<0.01$

Appendix Table 7: Interaction Effect between Access to NHV at Birth and Access to Preschool at Age 3 on Education, Income, and Survival; Rural/Urban Time Trends

Outcomes at Age 50
(1)
(2)
(3)
(4)

Yrs. School Basic Ed. Log Tot Inc Survival beyond age 65

\begin{tabular}{lcccc}
\hline Any Approved & $0.200^{* * *}$ & $-0.0273^{* * *}$ & $0.0339^{* * *}$ & $0.00522^{* *}$ \\
Preschool at Age 3 & {$[0.0701]$} & {$[0.00881]$} & {$[0.0129]$} & {$[0.00220]$} \\
NHV at Birth & $0.187^{* * *}$ & $-0.0251^{* * *}$ & $0.0359^{* * *}$ & $0.00500^{* *}$ \\
& {$[0.0585]$} & {$[0.00726]$} & {$[0.0119]$} & {$[0.00234]$} \\
Preschool x NHV & $-0.145^{* * *}$ & $0.0221^{* * *}$ & $-0.0189^{*}$ & -0.00283 \\
& {$[0.0509]$} & {$[0.00680]$} & {$[0.0107]$} & {$[0.00231]$} \\
\hline Mean, dept. var. & 12.07 & 0.299 & 12.56 & 0.903 \\
Observations (cells) & 3918 & 3918 & 3778 & 3918 \\
\hline
\end{tabular}

Notes: Each column reports the results from a separate regression. The units of analysis are municipality $\times$ birth-year cells. The sample is limited to the 140 municipalities that ever had an approved preschool by 1960 . When studying survival beyond age 65 , the sample is limited to only those individuals who have survived to at least age 50. All regressions include municipality and year-of-birth fixed effects as well as linear time trends interacted with rural/urban dummies. All regressions are weighted by the number of observations in each municipality $\times$ birth-year cell. Standard errors are clustered on the municipality level. Significance levels: ${ }^{*} \mathrm{p}<0.1 * * \mathrm{p}<0.05^{* * *} \mathrm{p}<0.01$ 
Appendix Table 8: Interaction Effect between Access to NHV at Birth and Access to Preschool at Age 3 on Education, Income, and Survival; with Municipality-Specific PreTrends

Outcomes at Age 50

(1) (2) (3)

(3) (4)

Yrs. School Basic Ed. Log Tot Inc Survival beyond age 65

\begin{tabular}{lcccc}
\hline Any Approved & $0.206^{* *}$ & $-0.0378^{* * *}$ & $0.0267^{*}$ & 0.00456 \\
Preschool at Age 3 & {$[0.0901]$} & {$[0.0120]$} & {$[0.0148]$} & {$[0.00393]$} \\
NHV at Birth & 0.0315 & 0.00164 & 0.0195 & 0.00807 \\
& {$[0.0662]$} & {$[0.00958]$} & {$[0.0253]$} & {$[0.00619]$} \\
Preschool x NHV & -0.0245 & -0.00267 & -0.00824 & -0.00568 \\
& {$[0.0684]$} & {$[0.00986]$} & {$[0.0266]$} & {$[0.00675]$} \\
\hline Mean, dept. var. & 12.07 & 0.299 & 12.56 & 0.903 \\
Observations (cells) & 3918 & 3918 & 3778 & 3918 \\
\hline
\end{tabular}

Notes: Each column reports the results from a separate regression. The units of analysis are municipality $\times$ birth-year cells. The sample is limited to the 140 municipalities that ever had an approved preschool by 1960 . When studying survival beyond age 65 , the sample is limited to only those individuals who have survived to at least age 50. All regressions include municipality and year-of-birth fixed effects as well as county-specific linear time trends. The regressions also include municipality fixed effects interacted with linear pre-trends. All regressions are weighted by the number of observations in each municipality $\times$ birthyear cell. Standard errors are clustered on the municipality level.

Significance levels: * $\mathrm{p}<0.1 * * \mathrm{p}<0.05 * * * \mathrm{p}<0.01$ 
Appendix Table 9: Interaction Effect between Access to NHV at Birth and Access to Preschool at Age 3 on Education, Income, and Survival; with All Municipality Controls

\begin{tabular}{|c|c|c|c|c|}
\hline & \multicolumn{3}{|c|}{ Outcomes at Age 50} & \multirow[b]{2}{*}{$\begin{array}{c}(4) \\
\text { Survival beyond age } 65\end{array}$} \\
\hline & $\begin{array}{c}(1) \\
\text { Yrs. School }\end{array}$ & $\begin{array}{c}(2) \\
\text { Basic Ed. }\end{array}$ & $\begin{array}{c}(3) \\
\text { Log Tot Inc }\end{array}$ & \\
\hline $\begin{array}{l}\text { Any Approved } \\
\text { Preschool at Age } 3\end{array}$ & $\begin{array}{l}0.0892^{* *} \\
{[0.0396]}\end{array}$ & $\begin{array}{r}-0.0155^{* * *} \\
{[0.00535]}\end{array}$ & $\begin{array}{c}0.00983 \\
{[0.00919]}\end{array}$ & $\begin{array}{l}0.00640^{* *} \\
{[0.00252]}\end{array}$ \\
\hline NHV at Birth & $\begin{array}{l}0.107^{* *} \\
{[0.0431]}\end{array}$ & $\begin{array}{l}-0.0131^{* *} \\
{[0.00578]}\end{array}$ & $\begin{array}{l}0.0232^{* *} \\
{[0.0106]}\end{array}$ & $\begin{array}{l}0.00642^{* *} \\
{[0.00261]}\end{array}$ \\
\hline Preschool x NHV & $\begin{array}{l}-0.0788^{*} \\
{[0.0419]}\end{array}$ & $\begin{array}{c}0.0106^{*} \\
{[0.00552]}\end{array}$ & $\begin{array}{l}-0.00774 \\
{[0.0102]}\end{array}$ & $\begin{array}{c}-0.00513^{* *} \\
{[0.00259]}\end{array}$ \\
\hline $\begin{array}{l}\text { Mean, dept. var. } \\
\text { Observations (cells) }\end{array}$ & $\begin{array}{l}12.07 \\
3918\end{array}$ & $\begin{array}{l}0.299 \\
3918\end{array}$ & $\begin{array}{l}12.56 \\
3778\end{array}$ & $\begin{array}{l}0.903 \\
3918\end{array}$ \\
\hline
\end{tabular}

Notes: Each column reports the results from a separate regression. The units of analysis are municipality $\times$ birth-year cells. The sample is limited to the 140 municipalities that ever had an approved preschool by 1960 . When studying survival beyond age 65 , the sample is limited to only those individuals who have survived to at least age 50. All regressions include municipality and year-of-birth fixed effects as well as county-specific linear time trends. The regressions also include municipality $\times$ year controls (interpolated for years without data) for: log population, percent female, percent urban, percent industrial, percent agricultural, percent paying income tax, log taxable income, percent paying property tax, percent voting for the social democratic party, percent voting for the radical liberal party, percent voting for the agrarian liberal party, and percent voting for the conservative party. All regressions are weighted by the number of observations in each municipality $\times$ birth-year cell. Standard errors are clustered on the municipality level. Significance levels: ${ }^{*} \mathrm{p}<0.1 * * \mathrm{p}<0.05^{* * *} \mathrm{p}<0.01$ 
Appendix Table 10: Interaction Effect between Access to NHV at Birth and Access to Preschool at Age 3 on Education, Income, and Survival; Drop Post-1949 Cohorts in 28 Municipalities with Worse NHV Data

\begin{tabular}{|c|c|c|c|c|}
\hline & \multicolumn{3}{|c|}{ Outcomes at Age 50} & \multirow[b]{2}{*}{$\begin{array}{c}(4) \\
\text { Survival beyond age } 65\end{array}$} \\
\hline & $\begin{array}{l}(1) \\
\text { Yrs. School }\end{array}$ & $\begin{array}{c}(2) \\
\text { Basic Ed. }\end{array}$ & $\begin{array}{c}(3) \\
\text { Log Tot Inc }\end{array}$ & \\
\hline $\begin{array}{l}\text { Any Approved } \\
\text { Preschool at Age } 3\end{array}$ & $\begin{array}{l}0.200^{* * *} \\
{[0.0487]}\end{array}$ & $\begin{array}{c}-0.0308^{* * *} \\
{[0.00623]}\end{array}$ & $\begin{array}{c}0.0174^{*} \\
{[0.00889]}\end{array}$ & $\begin{array}{l}0.00573^{* *} \\
{[0.00242]}\end{array}$ \\
\hline NHV at Birth & $\begin{array}{l}0.182^{* * *} \\
{[0.0491]}\end{array}$ & $\begin{array}{c}-0.0240^{* * *} \\
{[0.00640]}\end{array}$ & $\begin{array}{l}0.0269^{* * *} \\
{[0.0102]}\end{array}$ & $\begin{array}{l}0.00604^{* *} \\
{[0.00259]}\end{array}$ \\
\hline Preschool x NHV & $\begin{array}{c}-0.172^{* * *} \\
{[0.0433]}\end{array}$ & $\begin{array}{l}0.0255^{* * *} \\
{[0.00590]}\end{array}$ & $\begin{array}{c}-0.0156 \\
{[0.00958]}\end{array}$ & $\begin{array}{l}-0.00363 \\
{[0.00253]}\end{array}$ \\
\hline $\begin{array}{l}\text { Mean, dept. var. } \\
\text { Observations (cells) }\end{array}$ & $\begin{array}{l}12.07 \\
3694\end{array}$ & $\begin{array}{l}0.299 \\
3694\end{array}$ & $\begin{array}{l}12.56 \\
3554\end{array}$ & $\begin{array}{l}0.903 \\
3694\end{array}$ \\
\hline
\end{tabular}

Notes: Each column reports the results from a separate regression. The units of analysis are municipality $\times$ birth-year cells. The sample is limited to the 140 municipalities that ever had an approved preschool by 1960. For the 28 municipalities that do not establish NHV by 1949 in our data, we drop cohorts born in 1950-1957 since we do not have precise information on NHV initiation in those years. When studying survival beyond age 65, the sample is limited to only those individuals who have survived to at least age 50. All regressions include municipality and year-of-birth fixed effects as well as county-specific linear time trends. All regressions are weighted by the number of observations in each municipality $\times$ birth-year cell. Standard errors are clustered on the municipality level.

Significance levels: ${ }^{*} \mathrm{p}<0.1 * * \mathrm{p}<0.05 * * * \mathrm{p}<0.01$ 
Appendix Table 11: Interaction Effect between Access to NHV at Birth and Access to Preschool at Age 3 on Education, Income, and Survival; Drop Observations at Bottom of Education Distribution

Outcomes at Age 50

(1) (2) (3) $\quad(3)$

(3) (4)

Yrs. School Basic Ed. Log Tot Inc Survival beyond age 65

\begin{tabular}{lcccc}
\hline Any Approved & $0.220^{* * *}$ & $-0.0337^{* * *}$ & $0.0160^{*}$ & $0.00531^{* *}$ \\
Preschool at Age 3 & {$[0.0478]$} & {$[0.00620]$} & {$[0.00825]$} & {$[0.00236]$} \\
NHV at Birth & $0.190^{* * *}$ & $-0.0252^{* * *}$ & $0.0259^{* * *}$ & $0.00630^{* *}$ \\
& {$[0.0488]$} & {$[0.00625]$} & {$[0.00983]$} & {$[0.00262]$} \\
Preschool x NHV & $-0.189^{* * *}$ & $0.0282^{* * *}$ & -0.0129 & -0.00346 \\
& {$[0.0418]$} & {$[0.00580]$} & {$[0.00916]$} & {$[0.00254]$} \\
\hline Mean, dept. var. & 12.11 & 0.295 & 12.56 & 0.904 \\
Observations (cells) & 3918 & 3918 & 3778 & 3918 \\
\hline
\end{tabular}

Notes: Each column reports the results from a separate regression. The units of analysis are municipality $\times$ birth-year cells. The sample is limited to the 140 municipalities that ever had an approved preschool by 1960. Additionally, before collapsing the data, we randomly drop one percent of individual observations with seven years of schooling or less (i.e., those with the lowest education in our data). When studying survival beyond age 65, the sample is limited to only those individuals who have survived to at least age 50. All regressions include municipality and year-of-birth fixed effects as well as county-specific linear time trends. All regressions are weighted by the number of observations in each municipality $\times$ birth-year cell. Standard errors are clustered on the municipality level.

Significance levels: * $\mathrm{p}<0.1 * * \mathrm{p}<0.05 * * * \mathrm{p}<0.01$ 
Appendix Table 12: Interaction Effect between Access to NHV at Birth and Access to Preschool at Age 3 on the Education of the Next Generation

\begin{tabular}{lccc}
\hline & \multicolumn{3}{c}{ Child Outcomes at Age 25 } \\
\cline { 2 - 4 } & $\begin{array}{c}(1) \\
\text { Yrs.School }\end{array}$ & $(2)$ & $(3)$ \\
& $0.0464^{* *}$ & $-0.0163^{* * *}$ & Gym. \\
\hline Any Approved & {$[0.0223]$} & {$[0.00503]$} & $0.0103^{*}$ \\
Preschool at Age & 0.0166 & -0.00960 & {$[0.00551]$} \\
NHV at Birth & {$[0.0275]$} & {$[0.00593]$} & 0.00748 \\
& -0.0139 & 0.00825 & {$[0.00753]$} \\
Preschool x NHV & {$[0.0240]$} & {$[0.00526]$} & -0.00442 \\
& 12.34 & 0.225 & $0.00753]$ \\
\hline Mean, dept. var. & 3197 & 3197 & 0.253 \\
Observations (cells) & & & 3197 \\
\hline
\end{tabular}

Notes: Each column reports the results from a separate regression. The sample is limited to the children of females who were born in 1935-1957 in the 140 municipalities that ever had an approved preschool by 1960. The units of analysis are municipality $\times$ birth-year cells of the 1st generation of females with children. All regressions include municipality and year-of-birth fixed effects as well as county-specific linear time trends. All regressions are weighted by the number of observations in each municipality $\times$ birth-year cell. Standard errors are clustered on the municipality level.

Significance levels: ${ }^{*} \mathrm{p}<0.1 * * \mathrm{p}<0.05^{* * *} \mathrm{p}<0.01$

Appendix Table 13: Effect of Access to Preschool at Age 3 on Education, Income, and Survival; Early vs. Late Implementers

Outcomes at Age 50
(1)
(2)
(3)
(4)

Yrs. School Basic Ed. Log Tot Inc Survival beyond age 65

\begin{tabular}{lcccc}
\hline Any Approved & 0.0938 & -0.0122 & 0.00422 & $0.0145^{* * *}$ \\
Preschool at Age 3 & {$[0.127]$} & {$[0.0155]$} & {$[0.0319]$} & {$[0.00499]$} \\
Any Preschool x & 0.115 & -0.0204 & 0.0119 & $-0.0120^{* *}$ \\
Late Implementer & {$[0.127]$} & {$[0.0162]$} & {$[0.0314]$} & {$[0.00519]$} \\
\hline Mean, dept. var. & 12.07 & 0.299 & 12.56 & 0.903 \\
Observations (cells) & 3918 & 3918 & 3778 & 3918
\end{tabular}

Notes: Each column reports the results from a separate regression. The regression includes an interaction between the treatment variable and an indicator for the municipality being a "late implementer" (i.e., first preschool approval in 1940 or later). The units of analysis are municipality $\times$ birth-year cells. The sample is limited to the 140 municipalities that ever had an approved preschool by 1960 . When studying survival beyond age 65 , the sample is limited to only those individuals who have survived to at least age 50. All regressions include municipality and year-of-birth fixed effects as well as county-specific linear time trends. All regressions are weighted by the number of observations in each municipality $\times$ birth-year cell. Standard errors are clustered on the municipality level.

Significance levels: ${ }^{*} \mathrm{p}<0.1 * * \mathrm{p}<0.05^{* * *} \mathrm{p}<0.01$ 